\title{
Cycloaddition reactions of sugar-based olefins, nitrones and nitrile oxides. En route to saccharidic spiroisoxazoli(di)nes
}

\author{
Nadia Pellegrini Moïse* and Mylène Richard* \\ Université de Lorraine-CNRS, UMR 7053 L2CM, F-54506, Nancy (France)
}

Isoxazoline and isoxazolidine-containing compounds are privileged structures of interest, notably in synthetic and medicinal chemistry. These heterocycles can be obtained by 1,3dipolar cycloaddition reactions between an olefin and a nitrile oxide or a nitrone. This reaction generates the formation of one $\mathrm{C}-\mathrm{C}$ and one $\mathrm{C}-\mathrm{O}$ bond and up to three chiral centers in one step. In the present chapter, we aim to summarize and discuss reports of these cycloadditions on sugar olefins, with a focus on exo-methylene sugars or activated exoglycals, leading with high regio- and stereocontrol to saccharidic spiroisoxazoli(di)nes. Additional examples of cycloaddition reactions involving chiral nitrone, sugar nitrile oxide, sugar nitrone and also two chiral sugar partners will also be discussed. Due to the importance of the spiro structure in several biologically active compounds, these spiroheterocycles can be regarded as spironucleoside analogues, mimics of natural building blocks or multicyclic sugar scaffolds suitable for selective derivatization. Some of them thus showed promising biological properties as antibacterial agents or enzyme inhibitors. Moreover, the labile nature of the $\mathrm{N}-\mathrm{O}$ bond in the isoxazolidine ring makes it an attractive target for synthetic chemists. The reactivity of this scaffold has therefore been widely studied and the cycloadducts have been converted to other classes of compounds of interest. Examples of the biological relevance and synthetic use and reactivity of these spiro-sugars will be given in this chapter.

\section{Introduction}

The five-membered heterocycle isoxazolidine is part of several natural products and can be a useful synthetic intermediate due to the labile nature of the $\mathrm{N}-\mathrm{O}$ bond. As reported in an excellent review from I. Parrot and J. Martinez, [1] these compounds can be considered as natural building blocks analogues, i.e. nucleosides and carbohydrates analogues and can also be incorporated into peptidic sequences for the design of peptidomimetics. From a medicinal point of view, these derivatives provided many biological applications as cytotoxic, antiviral or antimicrobial compounds. These heterocycles are commonly obtained through the wellknown 1,3-dipolar cycloaddition between an olefin and a nitrone thus generating the formation of one C-C and one C-O bond [2-6].

Isoxazoline derivatives, the unsaturated parent of the five-membered heterocycle isoxazolidine, are also a class of heterocyclic compounds of significance, since they are frequently found in many compounds that showed significant biological activities [7]. Besides, they can be easily transformed into other functional groups, making them valuable compounds in synthetic chemistry. Nitrile oxide cycloaddition with olefin represents an easy route to this type of heterocycle $[8,9]$.

Reactivity of carbohydrate-derived olefins has been tested in this type of cycloadditions [1013]. In the present chapter, we aim to summarize and discuss reports of these cycloadditions 
on sugar olefins, with a focus on exo-methylene sugars or activated exo-glycals, leading with high regio- and stereocontrol to saccharidic spiro-isoxazoli(di)nes. Exo-glycals or $C$ glycosylidenes have an exocyclic double bond at the anomeric center [14, 15]. These compounds can be efficiently prepared by various olefination processes starting from sugar lactones and taking advantage of Wittig-type olefination or other organometallic reagents.

The first part of the present chapter is dedicated to exo-methylene sugars (anomeric and nonanomeric) as dipolarophiles in cycloaddition reaction with nitrile oxide and nitrone. We then focus on exo-glycals substituted by an electro-withdrawing group, labelled "activated exoglycals" and widely studied in our group with regard to their singular reactivity. Finally, the last part of this chapter describes some representative examples of 1,3-dipolar cycloaddition reactions of carbohydrate derived nitrones and nitrile oxides.

\section{Exo-methylene sugars as dipolarophiles}

In this first part, we report 1,3-dipolar cycloadditions with anomeric and non-anomeric exomethylene sugars or activated exo-glycals as dipolarophile partners.

\subsection{Anomeric exo-methylene sugars as dipolarophiles}

RajanBabu et al. described the first example of 1,3-dipolar cycloaddition of methylene exoglycals with nitrile oxide [16]. The tetrabenzyl protected derivative $\mathbf{1}$ efficiently reacted with carbomethoxynitrile oxide to stereospecifically give spiro-isoxazoline 2, considering steric hindrance on $\beta$ face (Scheme 1).

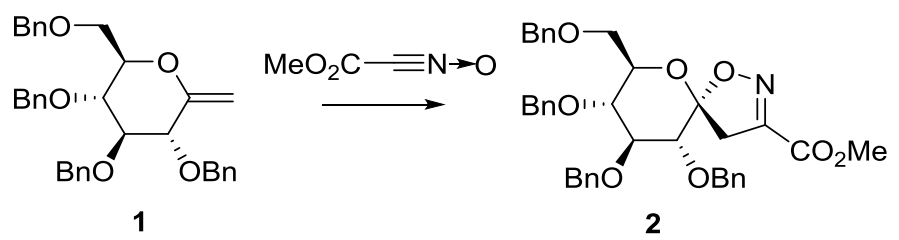

Scheme 1. Synthesis of the first saccharidic spiro-isoxazoline described by RajanBabu

Few years later, Lieberknecht and Bravo gave full experimental accounts of this reaction and applied it to Z- or E-configurated exocyclic enolethers 3 (Scheme 2) [17]. Starting from the $E$-configurated olefin, the cycloaddition reactions were performed with mesitonitrile oxide (stable monomer) in dichloromethane and trans-configurated cycloadducts $\mathbf{4}$ were obtained in excellent yields. With ethoxycarbonylnitrile oxide generated in situ, microwave irradiations were the most efficient for the cycloaddition on these trisubstituted alkenes $\mathbf{3}$, in particular for the less reactive 1-phenylenitol $\left(\mathrm{R}^{1}=\mathrm{Ph}\right)$. The diastereoisomeric ratio determined by NMR experiments confirmed the proposed structures for compounds $\mathbf{4}$ and $\mathbf{5}$, in agreement with the attack of the nitrile oxide to the less hindered face of the exo-glycal. Starting from $E$ configurated exo-glycals, the trans cycloadducts were mainly obtained (95:5) and the cis configurated cycloadducts were the main compounds when the reaction was performed on the $Z$-isomers. The regioselectivity was in line with trends found in nitrile oxide cycloadditions to trisubstituted alkenes [4]. 


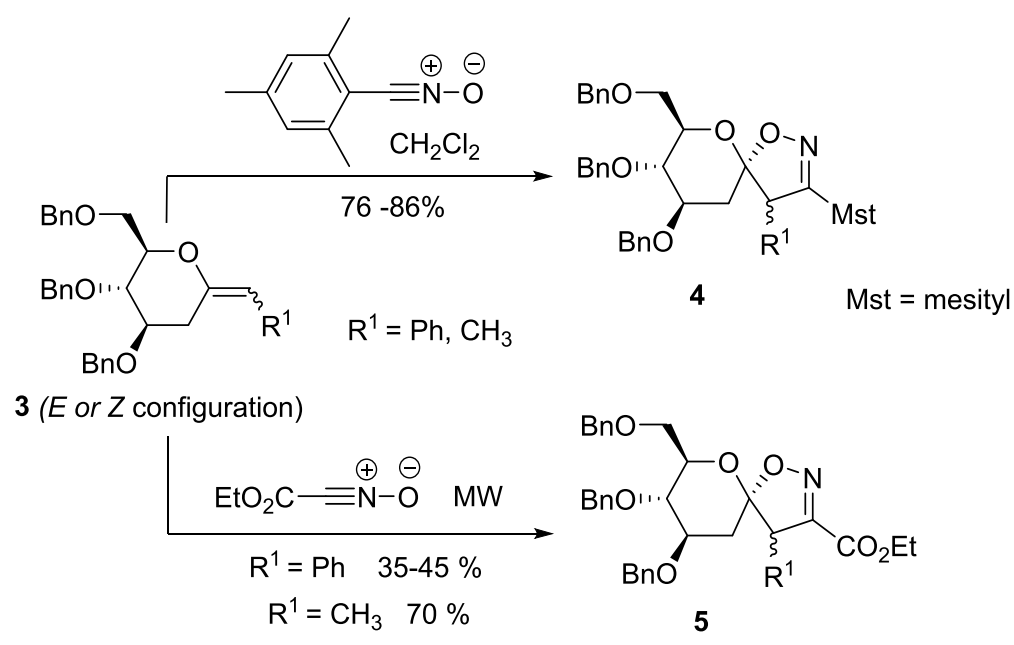

Scheme 2. Cycloadditions on Z- or E-configurated exocyclic enolethers

As part of their project concerning glucose derivatives as glycogen phosphorylase (GP) inhibitors, Praly et al. deeply developed the 1,3-dipolar cycloaddition of various aryl nitrile oxides to differently protected exo-glucals (Scheme 3) [18]. They demonstrated that the benzylated exo-glucal 1 afforded the corresponding spiro-isoxazoline $\mathbf{8}$ in high yields (83$94 \%$ ) with complete regio- and stereoselectivity established by 1D, 2D and NOESY NMR experiments. However, the reductive cleavage of the $\mathrm{N}-\mathrm{O}$ bond during hydrogenolysis of benzyl protecting group prompted them to envisage another hydroxyl protecting group like the triethylsilyl group (TES). On derivative 6, the cycloaddition of the aryl nitrile oxide did not give the expected cycloadduct. Finally, the acetylated methylene exo-glucal 7 was efficiently transformed in the corresponding adduct 9 subsequently deprotected by methanolysis. The obtained water-soluble spiro-isoxazolines were evaluated as glycogen phosphorylase inhibitors and showed $\mathrm{IC}_{50}$ values in the micromolar range. The X-ray structures of the enzyme-ligand complexes showed that this new family of glucose-based spiro-isoxazolines preferentially binds at the catalytic site of the enzyme retaining the less active T-state conformation [19]. Compound 12, prepared by this methodology, presented the best biological activity with a $\mathrm{Ki}$ value of $0.63 \mu \mathrm{M}$ for inhibition of $\mathrm{GPb}$ and was therefore deconstructed and used in an fragment-based binding evaluation [20]. Furthermore, 2naphthyl substituted glucopyranosylidene-spiroisoxazoline 12 was selected for further in vitro and in vivo evaluation on a rat model (Zucker fa/fa model) and the promising results indicated that this type of compounds can be considered as anti-hyperglycemic agents in the context of type 2 diabetes treatment [21]. 

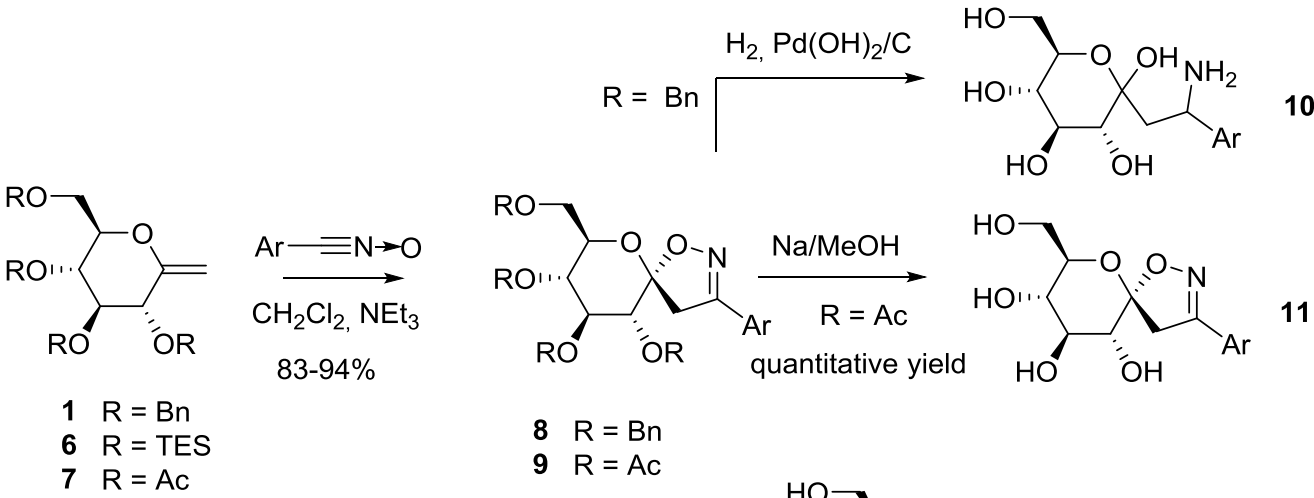

$8 \mathrm{R}=\mathrm{Bn}$

$9 \mathrm{R}=\mathrm{Ac}$

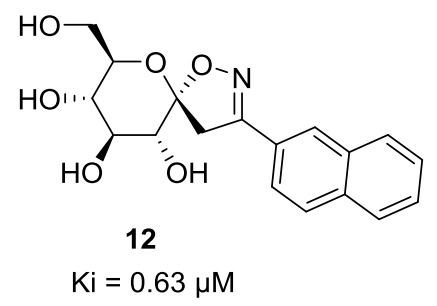

Scheme 3. Water-soluble spiro-isoxazolines as GP inhibitors

More recently, new spiro-isoxazolines from D-xylose were synthesized by cycloaddition of $O$ peracetylated exo-xylal 13 with various nitrile oxides prepared in situ by oxidation of the corresponding aromatic aldoximes 14 (Scheme 4) [22]. Here again, the configuration of the anomeric spiro-carbon was determined by NOE and similar stereoselectivities were observed in the formation of glucose- and xylose derived spiro-isoxazolines. The fully deprotected compounds 15 were evaluated toward $\mathrm{GPb}$ inhibition and showed moderate activity, highlighting the importance of the glucose moiety.

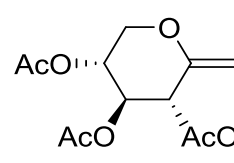

13

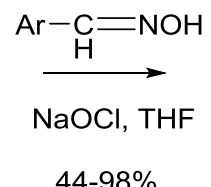

$44-98 \%$

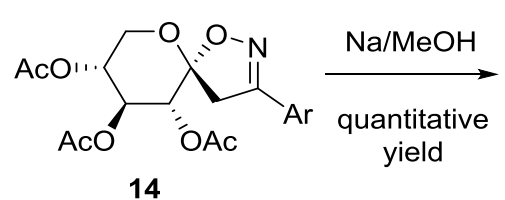

14

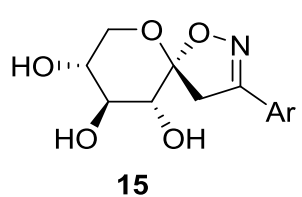

15

\section{Scheme 4. Xylose derived spiro-isoxazolines}

In the field of asymmetric catalysis, carbohydrates are excellent starting materials for the preparation of chiral auxiliaries. In this context, Vidal et al. efficiently used 1,3-dipolar cycloaddition of a bis(nitrile oxide) and methylene exo-glucal for the preparation of carbohydrate-based bis spiro-isoxazoline ligands like 16 (Scheme 5) [23]. These ligands were evaluated in a Pd-catalyzed Tsuji-Trost reaction but did not provide good results. Ring opening and formation of isoxazole, detected in the reaction mixture after addiction of $\mathrm{Pd}(\mathrm{II})$, probably explain the low yields. The carbohydrate-based bis spiro-isoxazoline ligands were also evaluated in $\mathrm{Cu}(\mathrm{I})$-catalyzed asymmetric imine alkynylation and, in this case, the addiction products were obtained in good yields. 

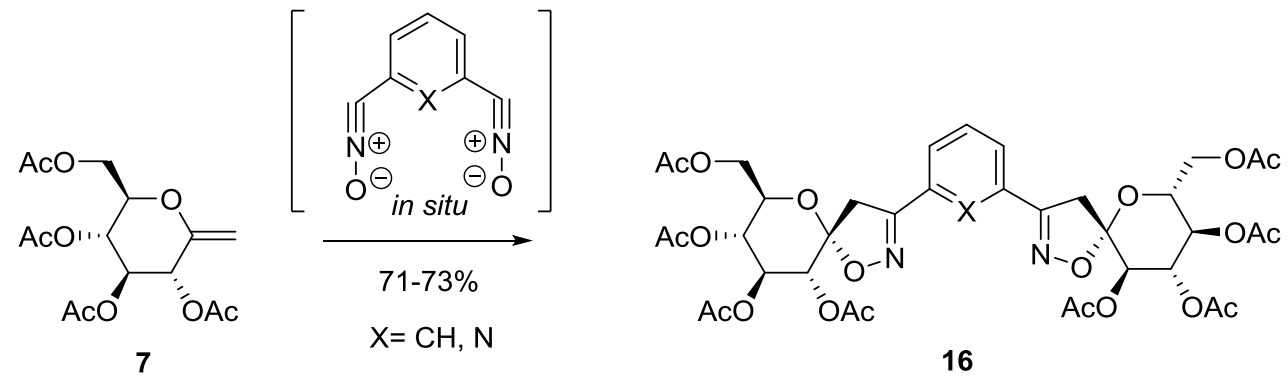

Scheme 5. Carbohydrate-based bis spiro-isoxazolines as ligands for asymmetric catalysis

1,3-Dipolar cycloaddition of nitrones with alkenes is widely used in organic synthesis and Ikegami et al. described this reaction on 1-methylenesugar 1 under $\mathrm{BF}_{3} \cdot \mathrm{Et}_{2} \mathrm{O}$ catalysis. At low temperature, the cyclization took place in a diastereoselective manner and afforded in good to excellent yields the corresponding spiro-isoxazolidines (Scheme 6) [24, 25]. The yields and the reaction stereoselectivities were slightly affected by the nature of the solvent, the temperature, the number of equivalents of catalyst and the steric hindrance of the nitrone. Although four diastereomers can be potentially obtained (two anomeric isomers with $\mathrm{R}$ and $\mathrm{S}$ configuration on C-3), only two anomeric isomers 17 and 19 or 18 and 20 with Rconfiguration on $\mathrm{C}-3$ were obtained, with $\alpha$-isomers 17 and 18 as the predominant compounds.

The 1,3-dipolar cycloaddition reactions were also performed on manno- and galactobenzylprotected exo-glycals and similar results were obtained. Concerning mannose derivative bearing an axial benzyloxy group on position 2 , an increase of $\beta$-stereoselectivity was observed ( $\alpha: \beta$ ratio, 5.4:1 to 1.9:1 depending on experimental conditions and on the nitrone substitution). In the same manner, the 1,3-dipolar cycloaddition on the acetylprotected 1-methylenesugar 7 was also performed under $\mathrm{BF}_{3} . \mathrm{OEt}_{2}$ catalysis and similar results were obtained.
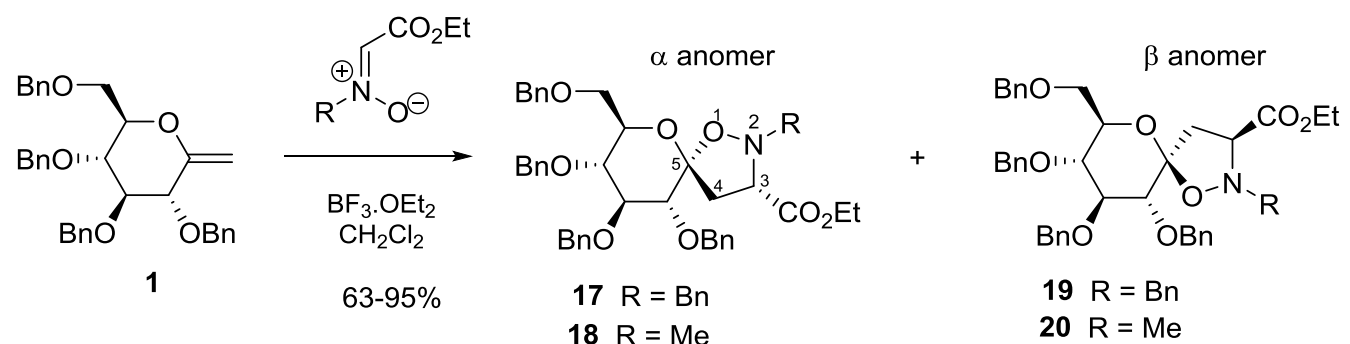

$\mathrm{R}=\mathrm{Bn}$, anomeric ratio $11.3: 1.0$

$\mathrm{R}=\mathrm{Me}$, anomeric ratio $9.1: 1.0$
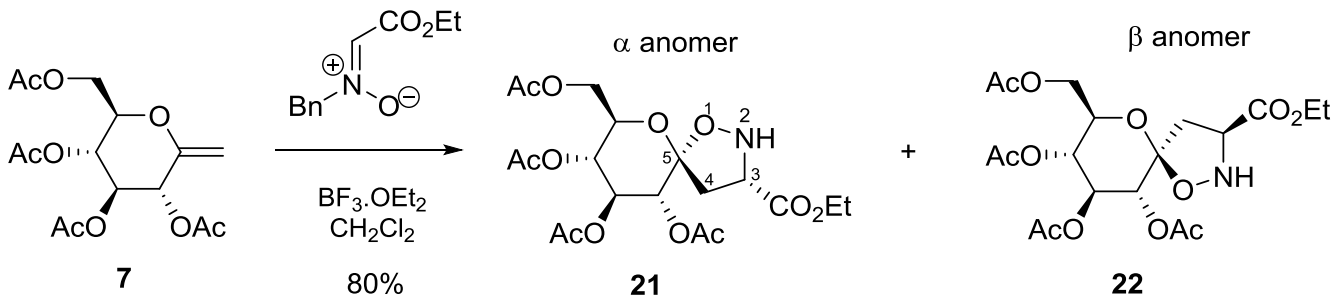

anomeric ratio $9.9: 1.0$ 
Scheme 6. Synthesis of spiro-oxazolidines by $\mathrm{BF}_{3} . \mathrm{Et}_{2} \mathrm{O}$ catalysis

Interested by the development of glycosyl amino acids, Ikegami et al. described a new access to $C$-glycosyl amino acids from spiro-isoxazolidines by reductive cleavage of the N-O bond (Scheme 7). The treatment of spiro-isoxazolidine $\mathbf{1 8}$ with $\mathrm{Zn}$ in acetic acid and acetic anhydride solution resulted in the formation of $C$-glycosyl amino acid $\mathbf{2 3}$ with retention of configuration at $\mathrm{C} 3$. Compound $\mathbf{2 4}$ resulting from intramolecular lactonization was also obtained.
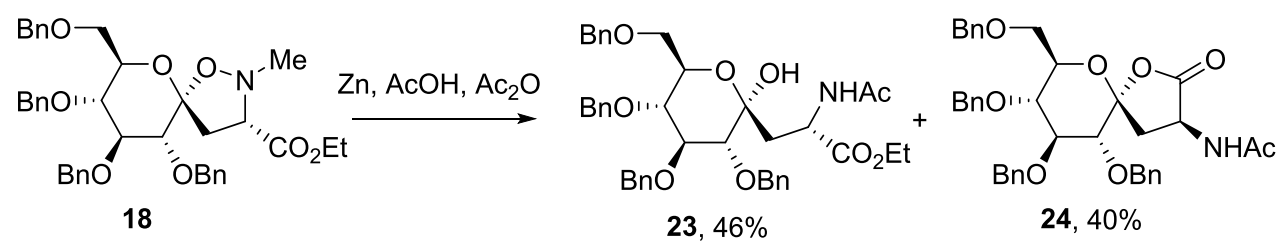

Scheme 7. Access to C-glycosyl amino acid by cleavage of $\mathrm{N}-\mathrm{O}$ bond

This efficient approach was employed by $\mathrm{Li}$ et al. for the preparation of novel spiroisoxazolidines by 1,3-dipolar cycloaddition with various nitrones [26]. Amino- $C$-glycosides 27 and 28 obtained as an anomeric mixture were sometimes difficult to separate because of their similar polarities (Scheme 8). Nevertheless, these compounds were useful intermediates for the preparation of oxazinanone derivatives containing sugar moiety and obtained by cyclization with triphosgene. As spironucleosides analogues, the biological activities against glycosidases and cytotoxicities of deprotected compounds 29 and $\mathbf{3 0}$ were evaluated and two derivatives showed selective inhibition properties against $\beta$-glucosidase and a slight antitumor activity.

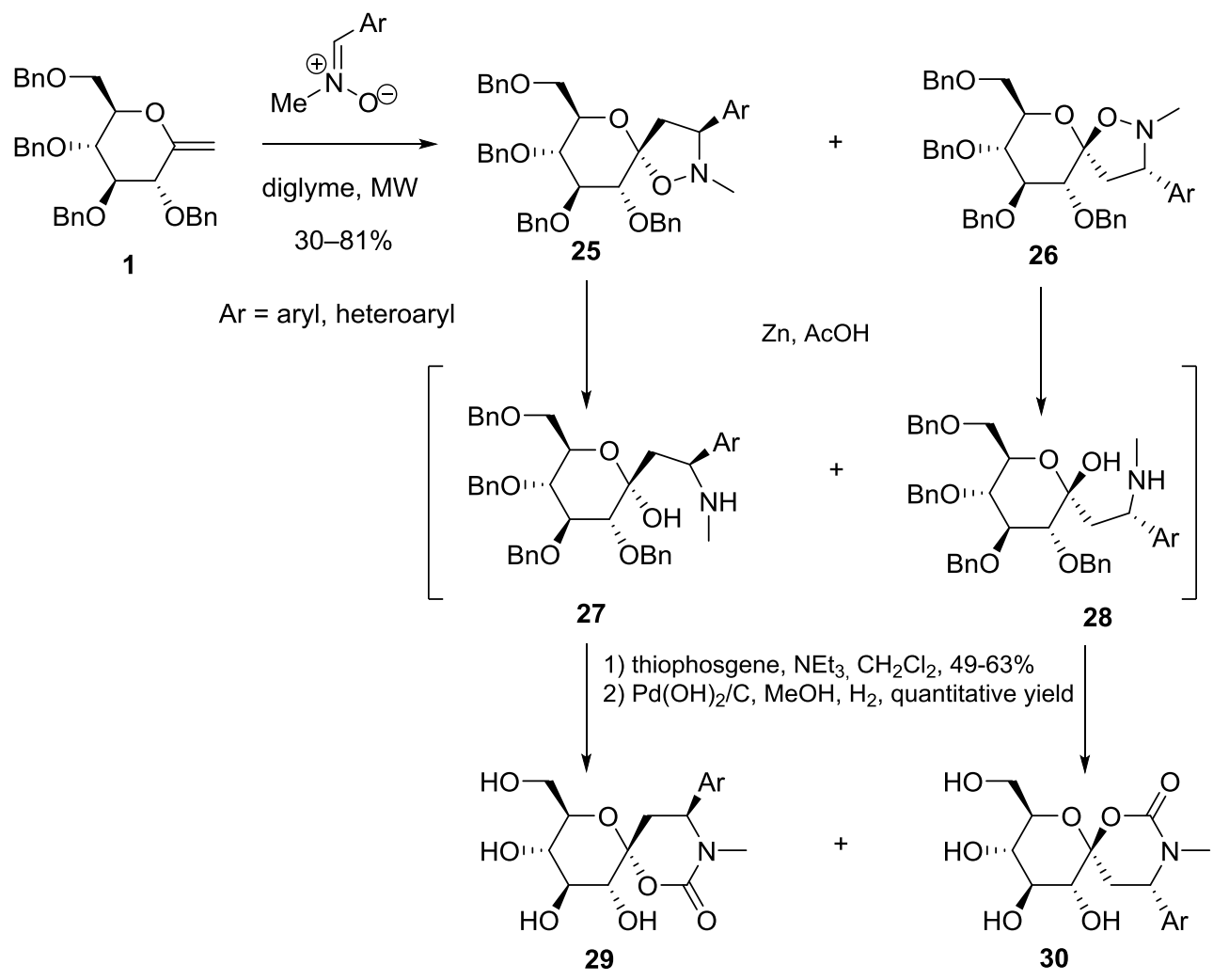


Scheme 8. Preparation of oxazinanone derivatives containing a sugar moiety

\subsection{Others exo-methylene sugars as dipolarophiles}

Carbohydrates are useful building blocks for the preparation of highly functionalized cyclopentane and cyclohexane rings found in biologically interesting compounds. In this context, Gallos et al. described the elegant synthesis of carbocycles $\mathbf{3 5}$ and $\mathbf{3 6}$ starting from hex-5-enopyranoside and pent-4-enofuranoside (Scheme 9) [27-29]. Cycloadditions of nitrile oxides with exo-glycals $\mathbf{3 1}$ and $\mathbf{3 2}$ respectively gave spiro-isoxazolines $\mathbf{3 3}$ and $\mathbf{3 4}$ in good yields. These compounds were efficiently transformed into the corresponding carbocycles by action of Ni Raney in a mixture of methanol and acetic acid. Functionalized carbocycles 35 and 36 were obtained by reductive opening of the heterocyclic ring and spontaneous intramolecular aldol-like condensation. The hydroxylated six- and five-membered cyclic enaminones were the main products of the reaction but the authors reported that by-products could be formed in some cases depending on the reaction conditions, the nature of substituents and the ring size.

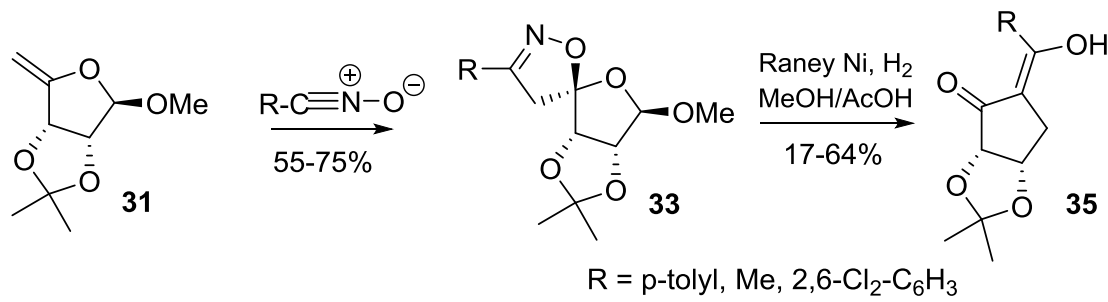

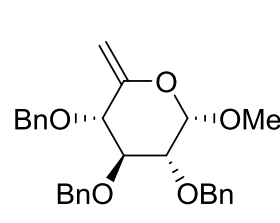

32

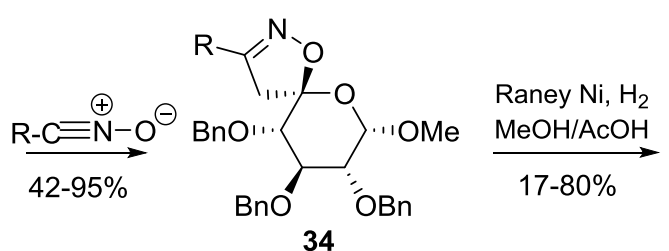

34

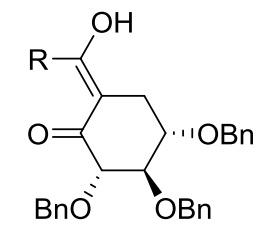

36

Scheme 9. Spiro-isoxazolines as intermediates for the synthesis of functionalized carbocycles

\subsection{Activated exo-glycals as dipolarophiles}

Unsaturated sugar olefins labelled "activated" possess an exocyclic double bond substituted by an electro-withdrawing group, giving them a capto-dative structure and a singular reactivity. Our group, headed by Yves Chapleur until 2014, developed a high-yielding, onestep method to prepare a series of activated exo-glycals. The saccharidic olefins were obtained in excellent yields as an easily separable mixture of $Z$ and $E$ isomers, via Wittig reaction on sugar lactones $[14,30]$. We investigated their behaviour in cycloaddition reactions with nitrile oxides and nitrones several years ago and we recently explored the potential biological activities of spiro-isoxazolidines based carbohydrates. 
Cycloaddition of activated exo-glycals $\mathbf{3 7}, \mathbf{3 8}$ and $\mathbf{3 9}$ was firstly tested with benzonitrile oxide (Scheme 10) [31, 32]. Reaction proceeded smoothly at room temperature but the expected spiro-isoxazolines 40 and 41 were not obtained and careful NMR examination indicated formation of open-chain compounds $\mathbf{4 2}$ and $\mathbf{4 3}$ in 52 or 72 and $35 \%$ yields respectively. Indeed, due to the basic conditions needed for in situ nitrile oxide formation, abstraction of acidic proton $\mathrm{H}_{4}$ promotes the aromatization into the corresponding isoxazoles via $\beta$ elimination of the sugar ring oxygen. Jimenez et al. had previously observed such rearrangement of activated olefins when reacted with nitrile oxides [33].
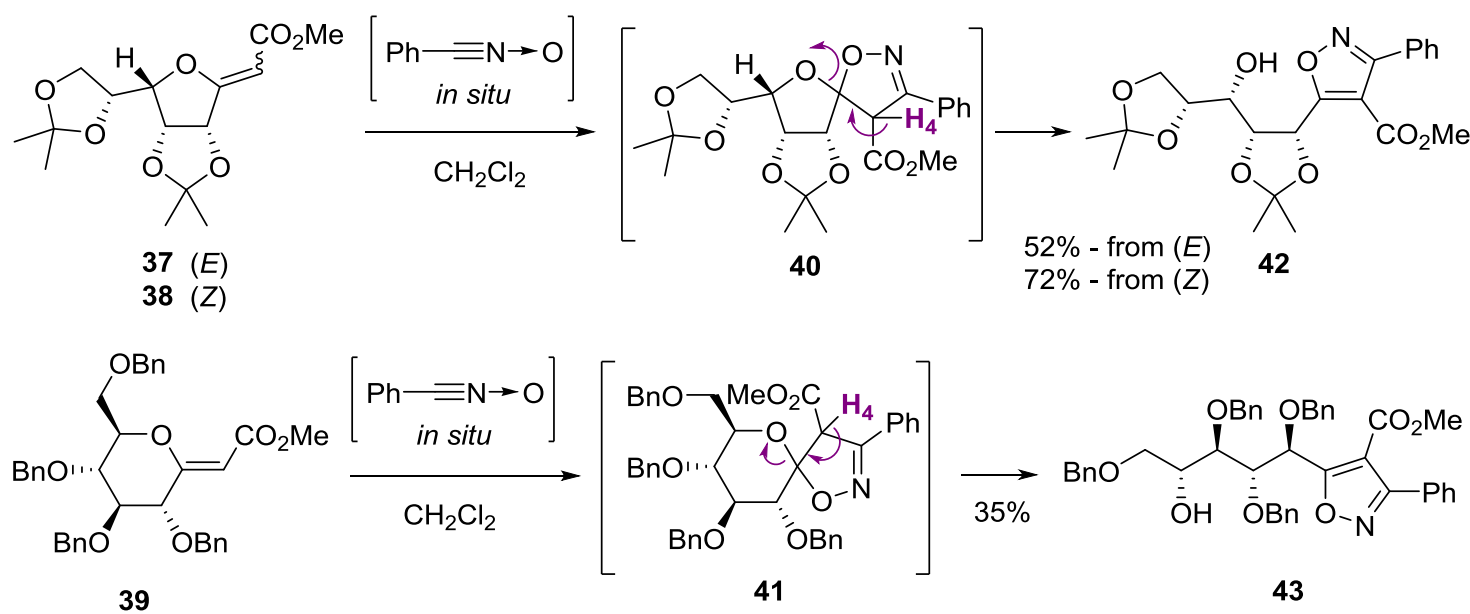

Scheme 10. Cycloadditions of activated pyrano- and furano-exo glycals with nitrile oxide

In similar fashion, the reactivity of these activated sugar olefins towards cycloaddition with nitrones was also explored in our group (Scheme 11). It is noteworthy that these reactions exclusively proceeded under microwave activation, no reaction occurring in standard thermal conditions. Cycloadducts were obtained in average to excellent yields depending on sugar and double bond configuration or nitrone substitution. On furano-E-exo-glycals 37 and 44, cycloaddition with unsubstituted nitrone $\left(\mathrm{R}^{2}=\mathrm{H}\right)$ generated only one diastereoisomer, implying a complete facial control due to the stereochemistry of the sugar moiety and the steric hindrance on $\alpha$ face. When considering more substituted nitrones $\left(R^{2} \neq H\right)$, two diastereoisomers at $\mathrm{C} 3$ where obtained, anti compounds 46 and 47 being the major ones as expected. However, the anti/syn ratio was also dependant on the nature of $\mathrm{R}^{3}$ substituent. Indeed, bulky substituents like benzyl group gave a 1:1 ratio, whereas a small substituent like a methyl group led to a 4:1 anti/syn ratio in the case of $\mathbf{3 7}$ (gulo derivative). Similar results were obtained on furano-Z-exo-glycals 38 and 45, except that anti selectivity was greatly enhanced with ribo olefin $\mathbf{4 5}$. However, when considering pyrano-exo-glycal 39, a different behaviour was observed. Cycloaddition with unsubstituted nitrone $\left(\mathrm{R}^{2}=\mathrm{H}\right)$ led to both anomers and four adducts 54-57 were obtained in case of reaction with substituted nitrones $\left(\mathrm{R}^{2} \neq \mathrm{H}\right)$, indicating an overall poor facial selectivity of the sugar ring. 


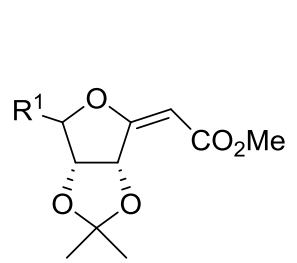

44 (ribo)

37 (gulo)

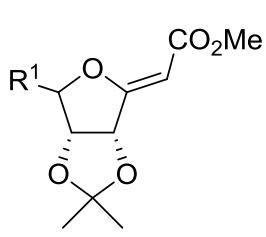

45 (ribo)

38 (gulo)

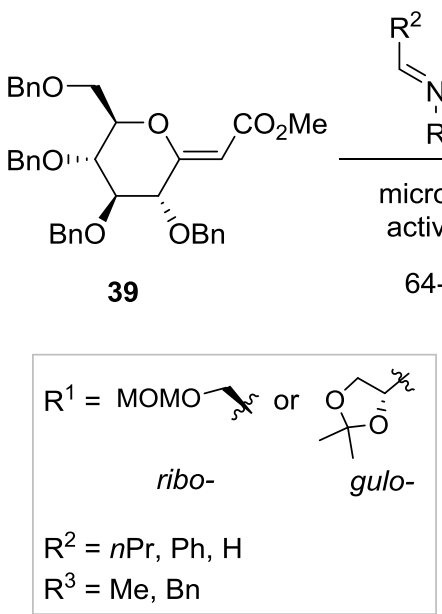

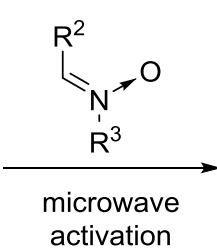

$50-92 \%$

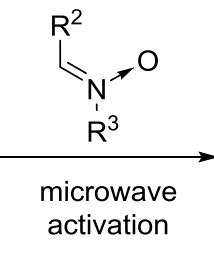

$57-96 \%$

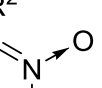

$\mathrm{R}^{3}$

microwave

ctivation

$4-86 \%$

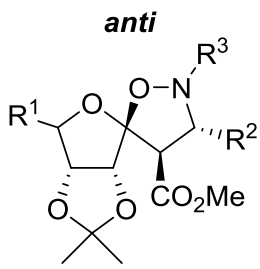

46

47

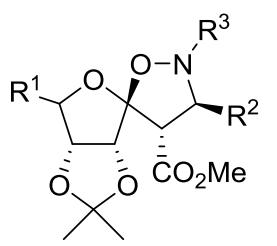

50

51

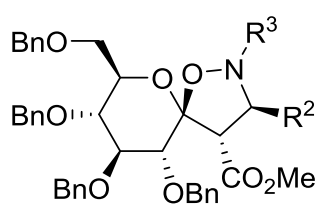

54

$+$

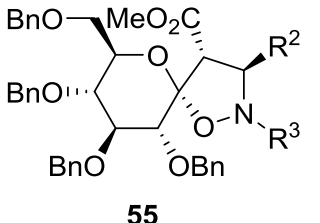

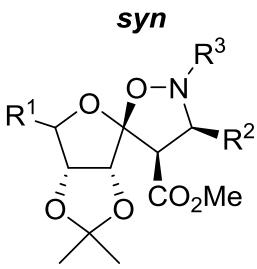

48

49<smiles>[R]C1O[C@@]2(ON1[R])[C@@H](C(=O)OC)C([R])N([R])[C@H]2OC(C)(C)C</smiles>

52

53

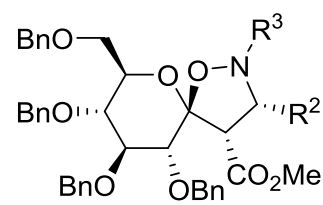

56

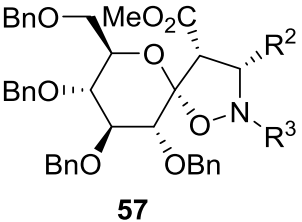

Scheme 11. Cycloadditions of activated pyrano- and furano- exo-glycals with nitrones

The stereochemistry of the cycloadducts and the anti/syn ratios were rationalized through postulated transition states (TS, Scheme 12). In endo TS case, steric hindrance between methyl ester and $\mathrm{R}^{2}$ group is minimized for both $E$ and $Z$ exo-glycals, whereas exo TS is congested and formation of corresponding syn compounds is therefore disfavoured.
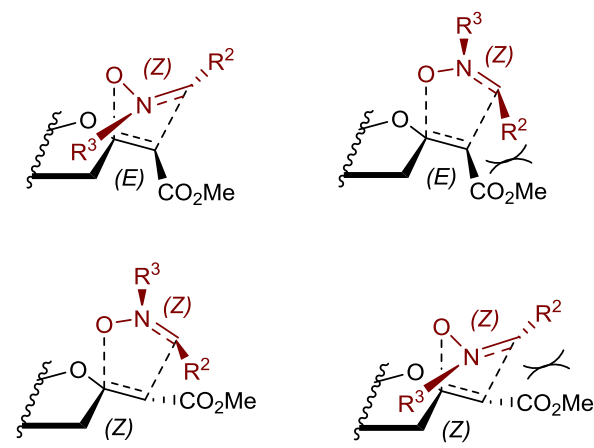

endo

exo

Scheme 12. Postulated transition states 
These spiro-isoxazolidines, easily deprotected in acidic media, can be considered as spironucleoside analogues and have thus potential biological properties. Indeed, the natural spironucleoside (+)-Hydantocidin displays both a plant growth regulatory function and a potent herbicidal activity harmless to microorganisms and mammals [34]. As an example, the deprotection of representative spiro-saccharide 49 was carried out with trifluoroacetic acid in water, giving 58 in quantitative yield (Scheme 13). It was established that these compounds are stable in acidic conditions and do not undergo furano to pyrano isomerization and that anomeric configuration is maintained through deprotection.

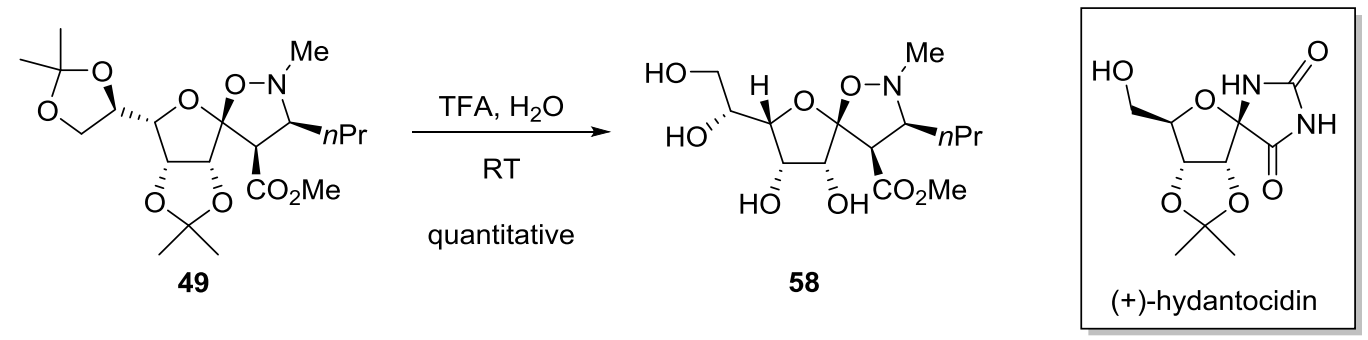

Scheme 13. Acidic deprotection of spiro-isoxazolines

To explore the potential biological activities of spiro-isoxazolidines based carbohydrates, we prepared a library of peptidomimetics for Neuropilin-1 (NRP-1) targeting (Scheme 14) [35]. NRP-1 is a transmembrane receptor of VEGFR-A implicated in various biological processes and notably angiogenesis. Our group has been interested in NRP-1 targeting for a few years with the aim of building a sugar-based peptidomimetic of the natural ligand of NRP-1 [36]. Using a sugar as a template provides a selected chirality and enables a precise spatial orientation of the substituents. In this context, we opted for a saccharidic spiro-isoxazolidine template presenting several anchoring points. Following previous studies on NRP-1/VEGFRA interactions, we functionalized the spiro scaffolds at two sites with arginine or arginine-like groups via copper azide alkyne catalysed reaction (compounds 59 and 60) or peptidic coupling (61 and 62) and tested their binding properties. However, given the moderate affinity of these peptidomimetics for NRP-1, the central bicyclic structure was probably too bulky for an appropriate binding to the receptor. Molecular modelling studies corroborated this hypothesis and helped us design more appropriate ligands [37, 38]. 


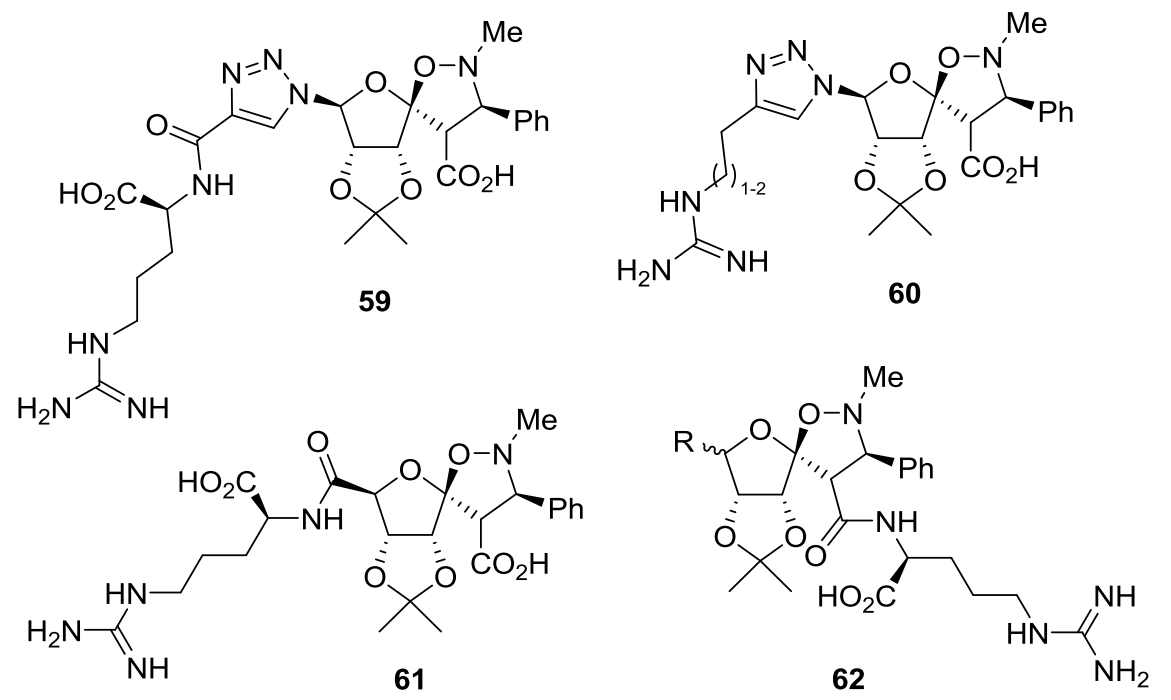

Scheme 14. Spiro-isoxazolidine based peptidomimetics for NRP-1 targeting

The labile nature of isoxazolidine $\mathrm{N}-\mathrm{O}$ bond makes it a valuable target for synthetic chemists and, as described by Li et al. [26, 39] and Gallos et al. [29], it can be easily cleaved with Zn in acetic acid and acetic anhydride or in Raney nickel hydrogenation conditions (cf I.1. above). During our work related to synthesis of NRP-1 peptidomimetics, we noted a similar cleavage of the $\mathrm{N}-\mathrm{O}$ bond during hydrogenolysis of 63 , leading to isoxazolidine ring opening and loss of N-benzylmethyl amine moiety (Scheme 15).

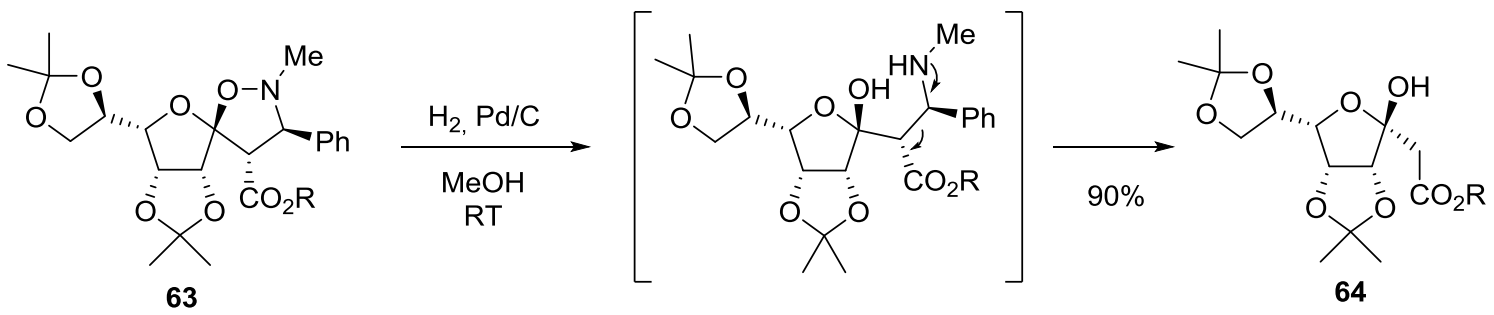

Scheme 15. Isoxazolidine cleavage by hydrogenolysis

Very few examples are reported on cycloadditions reactions between two sugar partners, although this reaction could lead to highly chiral analogues of natural products like hikosamine or tunicamycins (Scheme 16) [40]. Indeed, this synthetic approach would benefit of the easiness of isoxazolidine ring opening combined to the facial selectivity and chirality of the sugar moieties.<smiles>N[C@H]1[C@@H](O)[C@@H](O)C(O)O[C@H]1[C@H](O)[C@H](O)[C@H](O)[C@H](O)CO</smiles>

Hikosamine<smiles>[R6]C1O[C@H](C[C@H](O)[C@@H]2O[C@@H](n3ccc(=O)[nH]c3=O)[C@H](O)[C@@H]2O)[C@H](O)[C@@H](O)[C@@H]1NC(=O)/C=C/CC(C)C</smiles>

Tunicamycins 
Scheme 16. Long chain sugars natural products

In this context, we more recently examined the cycloaddition of activated exo-glycals with carbohydrate-derived nitrones (Scheme 17). Nitrones were beforehand prepared by Swern oxidation of protected L-threitol followed by reaction with appropriate hydroxylamines. Then, starting from mannose olefins 65 or 66 , cycloaddition with nitrone 67 led to a single product in both cases, 68 and 69 respectively. This indicates an excellent facial selectivity induced by steric hindrance on $\beta$ face of exo-glycals. Moreover, due to the bulkiness of benzyl group on nitrone 67, only one C-3 diastereoisomer was obtained. Configurations at C-3/C-4 were established from the coupling constants between protons $\mathrm{H}-4$ and $\mathrm{H}-3$ and indicated an anti configuration for adduct 68 and a syn configuration for 69. These observations may be rationalized by analysis of postulated transition states. In the case of Z-exo-glycal, endo TS minimizes the steric hindrance, leading to compound 68 exclusively. For E-exo-glycal 66, interactions of the nitrone benzyl group with the sugar ring destabilizes the endo transition state and formation of $\mathbf{6 9}$ probably arose from an exo TS. When performed with less hindered nitrone $\mathbf{7 0}$ on exo-glycal $\mathbf{6 5}$, the same reaction led to the formation of two C-3 diastereoisomers $\mathbf{7 1}$ and $\mathbf{7 2}$ in excellent yield, compound $\mathbf{7 1}$ (anti configuration) being the major product.

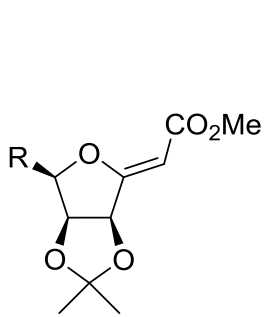

65

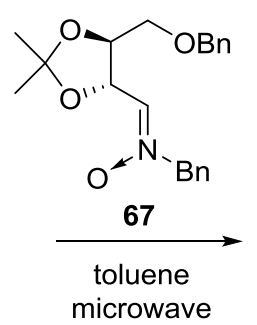

$83 \%$

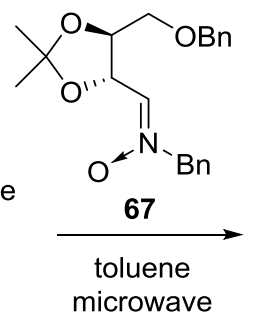

$60 \%$

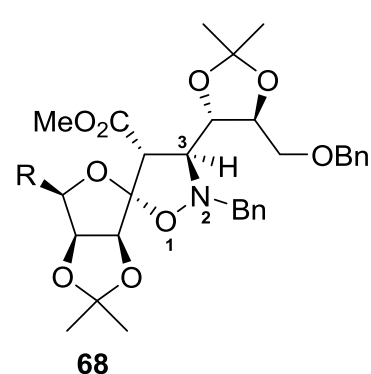

68

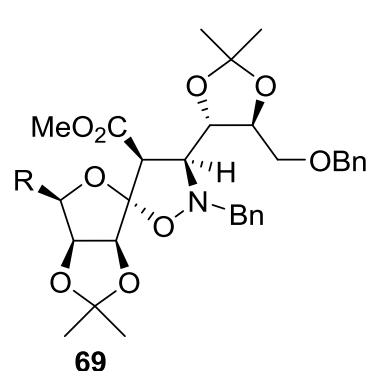

69
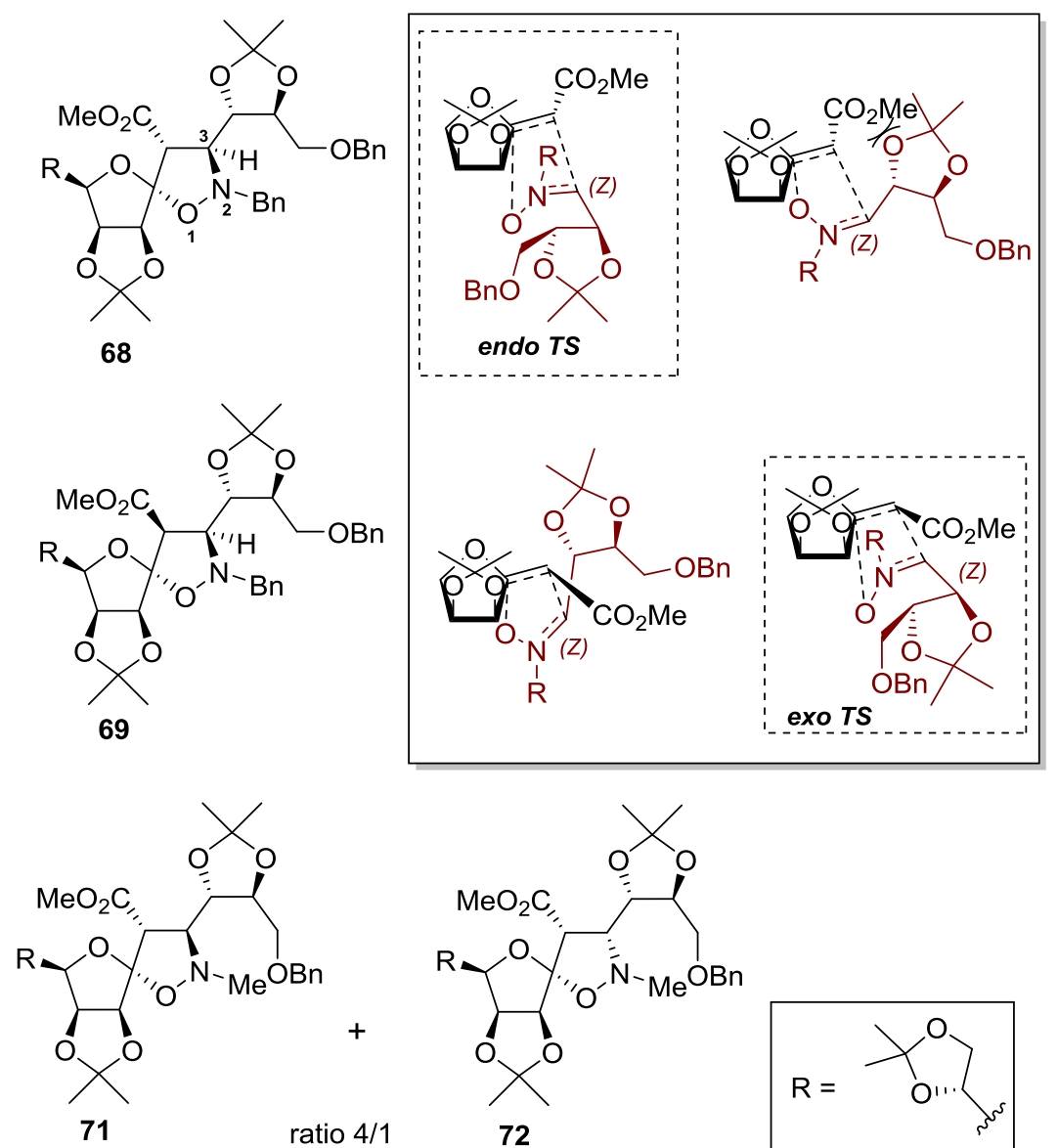

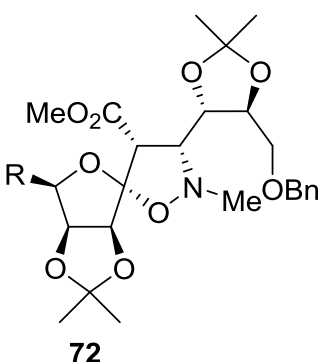

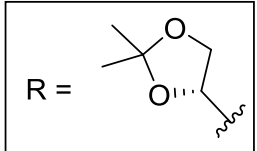

Scheme 17. Cycloadditions with open-chain sugar olefins. 
As seen in these examples, cycloaddition between carbohydrate based nitrones and enoates is a valuable way to connect two sugars via generation of three new chiral centers, leading to complex carbohydrates and up to nine chiral centers. The remarkable selectivity of sugarbased nitrones has been explored on cycloaddition reactions with various olefins and the last part of this chapter focuses on some representative examples.

\section{Carbohydrate derived nitrones and oximes as 1,3-dipole}

This part is dedicated to sugar-based nitrones and nitrile oxides involved in cycloaddition reactions with various olefins and leading to saccharidic spiroisoxazolines and spiroisoxazolidines.

\subsection{Non-anomeric sugar nitrones or nitrile oxides}

The 1,3-dipolar cycloaddition of aldonitrones [8] and in particular sugar derived aldonitrones prepared in situ from hydroxylamine derivatives (compound $\mathbf{7 3}$ for example) was fully described by Vasella et al. [41, 42] and allowed the synthesis of several interesting biologically active molecules. Similar reactions with more hindered sugar derived ketonitrones like compound $\mathbf{7 4}$ were first described by Tronchet et Mihaly but the yields were not reported (Scheme 18) [43].

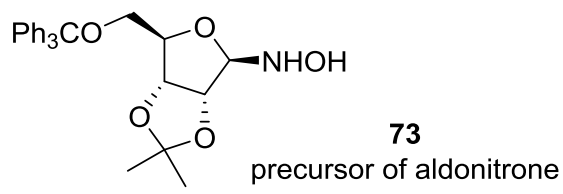

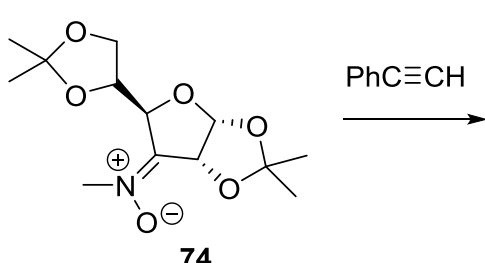

sugar derived ketonitrones

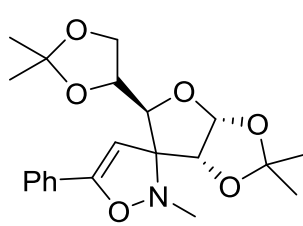

75

Scheme 18. 1,3-Dipolar cycloaddition reactions of carbohydrate derived aldonitrones and ketonitrones

Later, nitrone 76 was prepared from the corresponding 4-oxo-mannopyranose derivative and the cycloaddition reaction with ethyl vinyl ether afforded in a regioselective manner cycloadducts 77 and 78 with a 6:1 ratio (Scheme 19) [44]. An intramolecular version of this reaction was next investigated on various pyrano or furano derivatives bearing a 4-O-allyl group as the internal dipolarophile. For example, on compound 79 ( $\alpha$ C4-hydroxyl); the reaction proceeded with good yield and in this case a single stereoisomer $\mathbf{8 0}$ was isolated. Starting from 81 isomer ( $\beta$ C4-hydroxyl), the exclusive formation of the adduct 82 was observed. These results clearly showed that the stereochemistry of the reaction depends on the $\mathrm{C} 4$ configuration. Others heterocyclic and carbocyclic systems were efficiently obtained by this method from carbohydrates derivatives. 

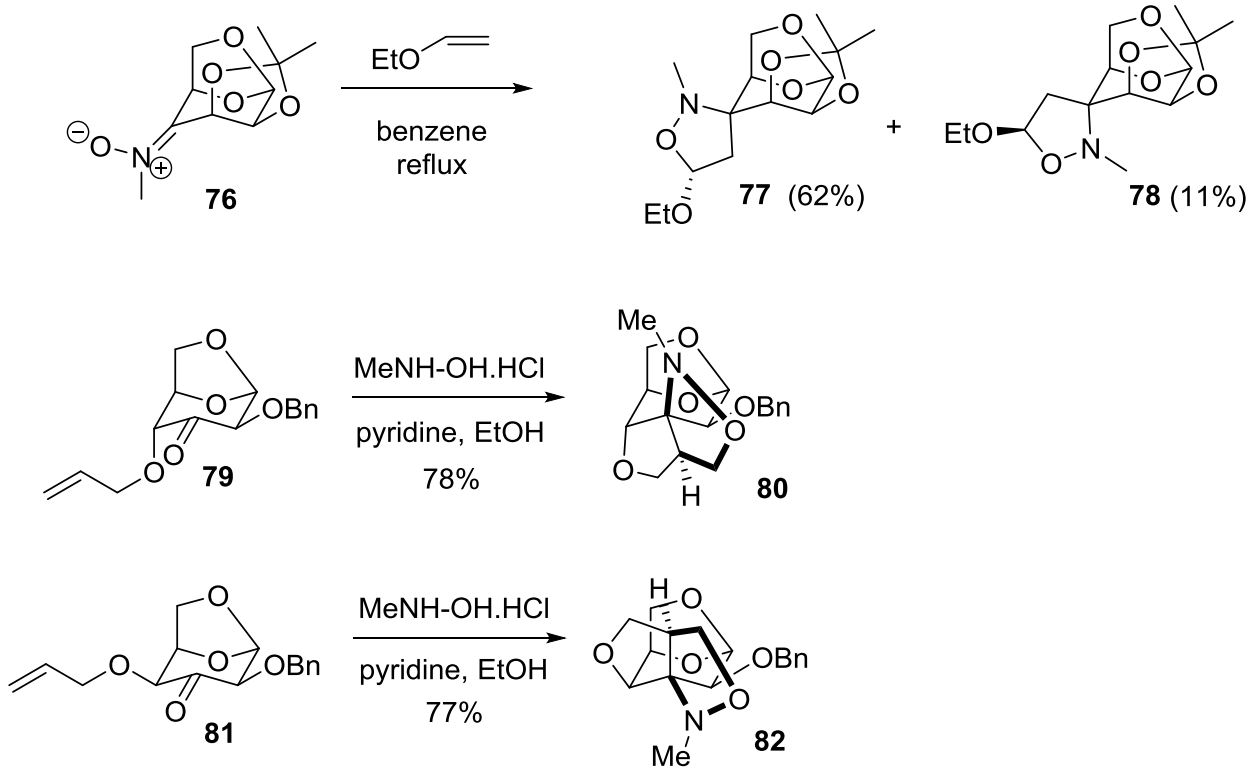

Scheme 19. Examples of heterocyclic and carbocyclic systems obtained by 1,3-dipolar cycloaddition reactions

Nucleosides analogues with $\mathrm{C} 2$ ' or $\mathrm{C} 3$ ' spiro substitutions were prepared via intramolecular cycloaddition reactions between an electron-rich olefin and a vicinal nitrone (Scheme 20) [45, 46]. As an example, for synthesis of 3'-substituted spiro-isoxazolidine thymidine derivative 84, the reaction of 3'-ketone with $N$-methylhydroxylamine hydrochloride gave the 3'methylnitrone $\mathbf{8 3}$ susbsequently treated with ethyl vinyl ether. The cycloaddition reaction occurred in a diastereospecific manner, giving only compound $\mathbf{8 4}$ in $95 \%$ yield. The stereochemistry of the cycloadduct was explained by a postulated transition state and the C3'(or C2'-) configuration was proved by 1D NOE difference spectroscopy. Other 2' or 3'- spiroisoxazolidines derivatives were efficiently prepared by this methodology and consitute a new class of nucleoside analogues.
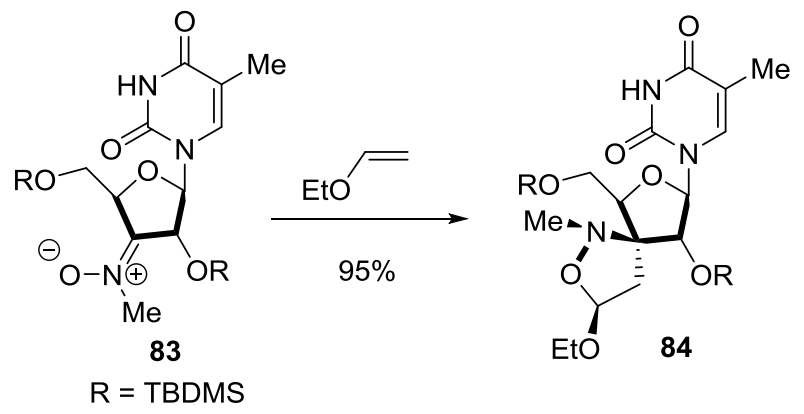

Scheme 20. Examples of spiro-isoxazolidine derivatives of thymidine obtained by 1,3-dipolar cycloaddition reactions

The 1,3-dipolar cycloaddition of sugar ketonitrones with differently substituted dipolarophiles was studied by Alonso et al. [47]. The aim of this work was to take advantage of this useful synthetic procedure to get original compounds with nitrogenated quaternary centers. The authors firstly developed highly efficient intramolecular procedures with mono-, di- and trisubstituted olefins. They then turned to an intermolecular version with ketonitrone $\mathbf{8 5}$ 
prepared by treatment of the corresponding lactone with methylhydroxylamine hydrochloride in pyridine (Scheme 21). When heated in refluxing benzene with ethyl vinyl ether, nitrone 86 led to cycloadducts $\mathbf{8 7}$ and $\mathbf{8 8}$ in $73 \%$ overall yield. The reaction occurred in a complete regioselective manner, but with a moderate stereoselectivity as attested by the $\mathbf{8 7 / 8 8}$ ratio (6:1). To go further, the authors studied the reactivity of ketonitrone 90, directly available from D-glucurono-3,6-lactone. This tricyclic compound is an attractive system due to its high facial selectivity and can thus led to only one stereoisomer. When refluxed in benzene with phenylacetylene, expected spiro-isoxazolidine 91 was obtained in a total regio- and stereoselective manner. A complete regio and stereocontrol was also observed with allyl alcohol, leading to cycloadduct $\mathbf{9 2}$ in excellent yield. Only one stereoisomer was obtained but the configuration of the newly created asymetric carbon bearing the hydroxymethyl group was not established. It is worthy to note that the use of substituted dipolarophiles like 2methyl-2-propen-1-ol gave low diastereoselectivity.

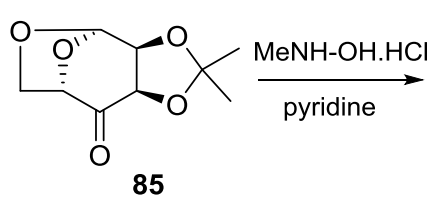

85

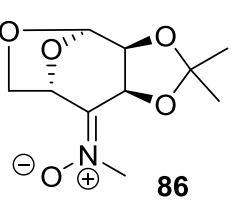

86
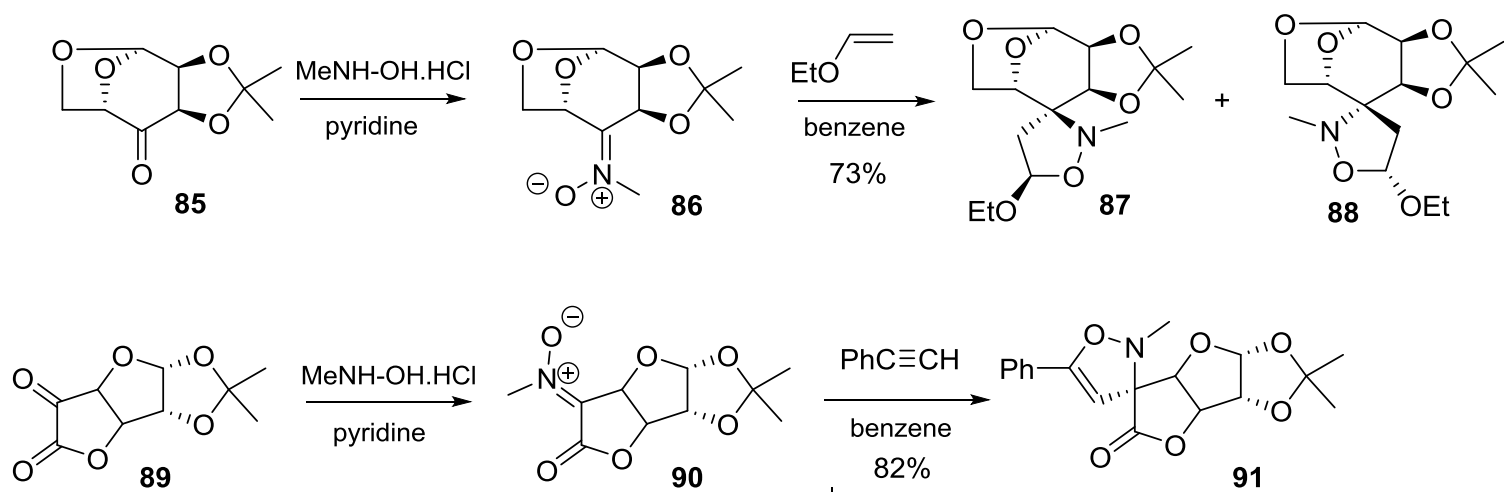

$\stackrel{\mathrm{MeNH}-\mathrm{OH} . \mathrm{HC}}{\longrightarrow}$ pyridine
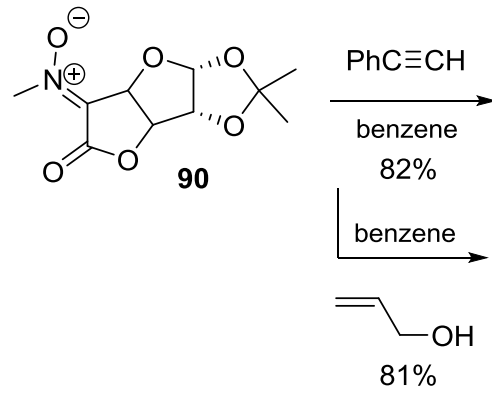

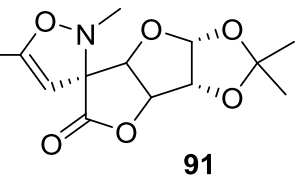

91

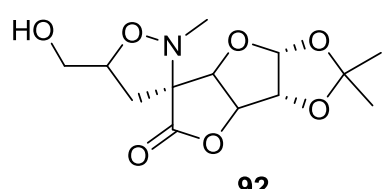

Scheme 21. 1,3-dipolar cycloaddition of sugar ketonitrones

\subsection{Anomeric sugar based nitrones}

Chiral isoxazolidines bearing a sugar moiety have been extensively developped by Yokoyama et al. via a tanden Michael addition-1,3-dipolar cycloaddition [12, 48, 49]. These authors described the preparation of sugar nitrone 94 by reaction of sugar oxime 93 with methyl acrylate. The intermediate nitrone 94, prepared according to Griggs's reaction [50], was not isolated and reacted with another methyl acrylate molecule in a 1,3-dipolar cycloaddition reaction (Scheme 22). For this purpose, the mixture was heated in dry toluene in a sealed tube and gave the spiro-isoxazolidine $\mathbf{9 5}$ in a regio- and stereoselective manner. The cycloadducts 96 and 97 were obtained in $48 \%$ and $37 \%$ yield respectively by reaction with methyl vinylketone. The stereochemistry of compound 96 at $\mathrm{C} 3$ position was umambigusly determined by X-ray analysis. When reacted with acrylonitrile, an inseparable mixture of C-3 stereoisomers 98 was obtained. 

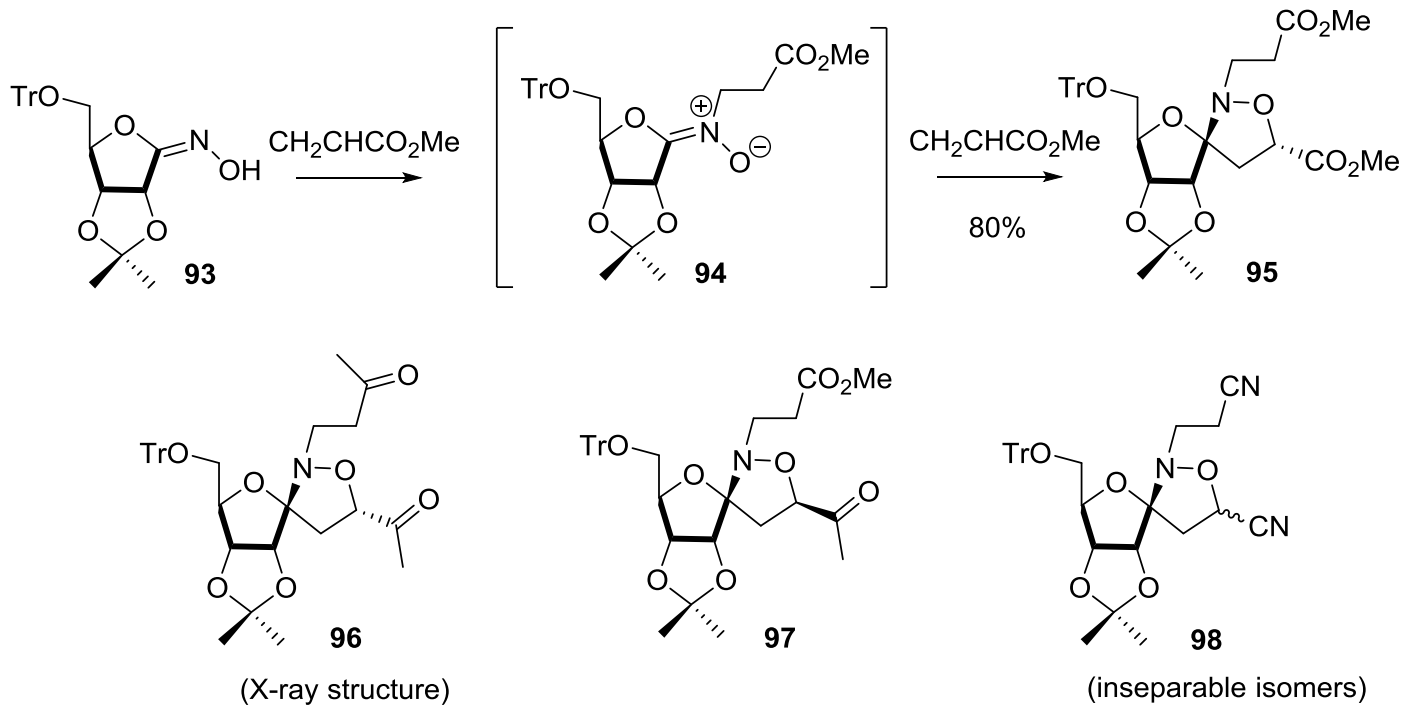

Scheme 22. Sugar hydroximolactones in a tandem Michael addition-1,3-dipolar cycloaddition

Yokoyama et al. also reported the preparation of two new bicyclic nucleosides 100 and $\mathbf{1 0 1}$ [51]. The formation of these original fused sytems is presumed to proceed through a spiroisoxazoline intermediate 99 prepared by cycloaddition of dimethyl acetylenedicarboxylate and sugar oxime 93. Instability of spiro adduct 99 prompts the opening and consecutive closure of the sugar ring and $\mathbf{1 0 0}$ and $\mathbf{1 0 1}$ were obtained in a 2.7:1 ratio as diastereoisomeric mixture in $85 \%$ overall yield (Scheme 23 ).

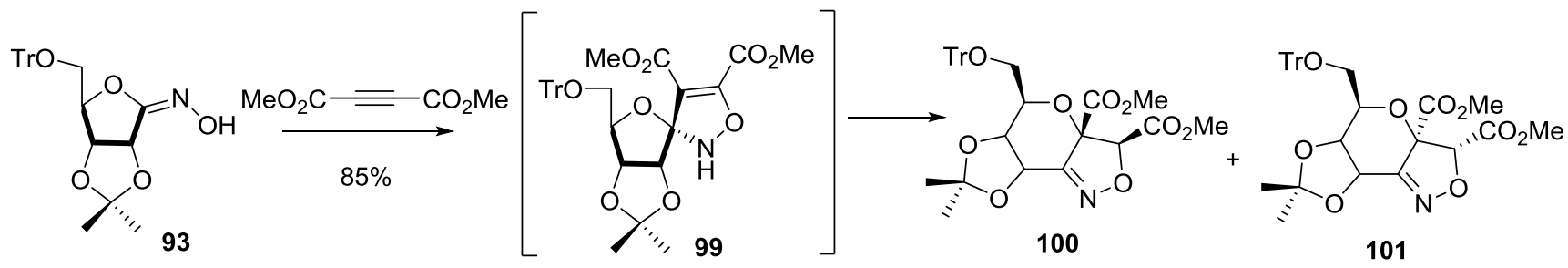

Scheme 23. New bicyclic nucleosides from hydroxyiminolactone

\subsection{Reactions of carbohydrate derived nitrones and nitrile oxides on exo-methylene sugars}

In connection to their work on exo-methylene sugars (cf I.1), Ikegami and coworkers carried out the diastereoselective cycloaddition of sugar nitrone 108 on exo-glycals 1,102 and 103 (Scheme 24) [39]. On glucose derivative 1, reaction afforded $\alpha$ and $\beta$ spiro-isoxazolidines 104 and 107 with a 3:1 ratio in a 69\% overall yield. NOE correlations analysis enabled assignment of absolute configuration of C-6 as $R$ for both anomers. In the case of galacto- and manno-exo-glycals 102 and 103, only $\beta$ anomers 105 and 106 were obtained in average yields. 


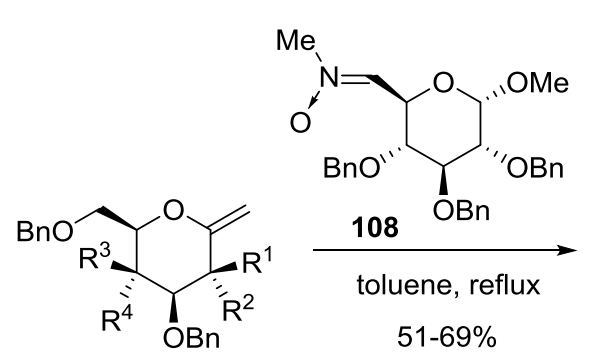

1 (gluco) $\mathrm{R}^{1}=\mathrm{R}^{3}=\mathrm{H}, \mathrm{R}^{2}=\mathrm{R}^{4}=\mathrm{OBn}$

102 (galacto) $\mathrm{R}^{1}=\mathrm{R}^{4}=\mathrm{H}, \mathrm{R}^{2}=\mathrm{R}^{3}=\mathrm{OBn}$

103 (manno) $\mathrm{R}^{2}=\mathrm{R}^{3}=\mathrm{H}, \mathrm{R}^{1}=\mathrm{R}^{4}=\mathrm{OBn}$
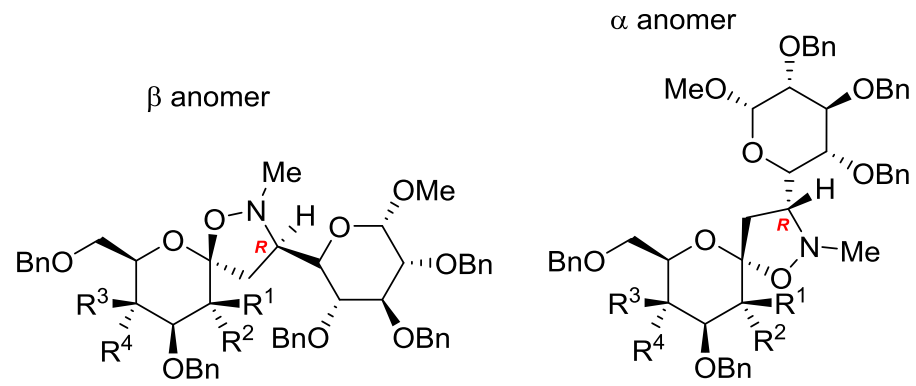

104

anomeric ratio $3: 1 \quad 107$

105

106

Scheme 24. Reaction between exo-glycals and sugar nitrone

Similarly, cycloadditions between pyrano-exo-glycals 1, 102 and 103 and nitrile oxides were reported by Zhang et al. (Scheme 25) [52]. Preparation of sugar nitrile oxides a-c involved formation of oximes from aldehydes followed by oximes chlorination and finally dehydrochlorination of oximinoyl halides. Handling of nitrile oxides a-c proved complex and they were used in the next step without work-up or purification. When cycloaddition reaction was carried out on glucose and mannose derivatives 1 and 103, only $\alpha$ anomers 109a-c and 111a-c were obtained in all cases, indicating a diastereoselective addition. Concerning olefin 102, reaction was stereoselective with nitrile oxides $\mathbf{b}$ and $\mathbf{c}$ but a 3:2 anomeric mixture was obtained with nitrile oxide a. It should be noted that a nitrile oxide dimer side product was also formed in all cases, probably due to instability of nitrile oxides a-c. After deprotection of the saccharidic spiro-isoxazolines by catalytic hydrogenation, their biological properties as glycosidases inhibitors were tested. Although the compounds showed a low inhibitory effect, they were selective between glycosidases, with a higher inhibitory activity against $\alpha$-amylase.

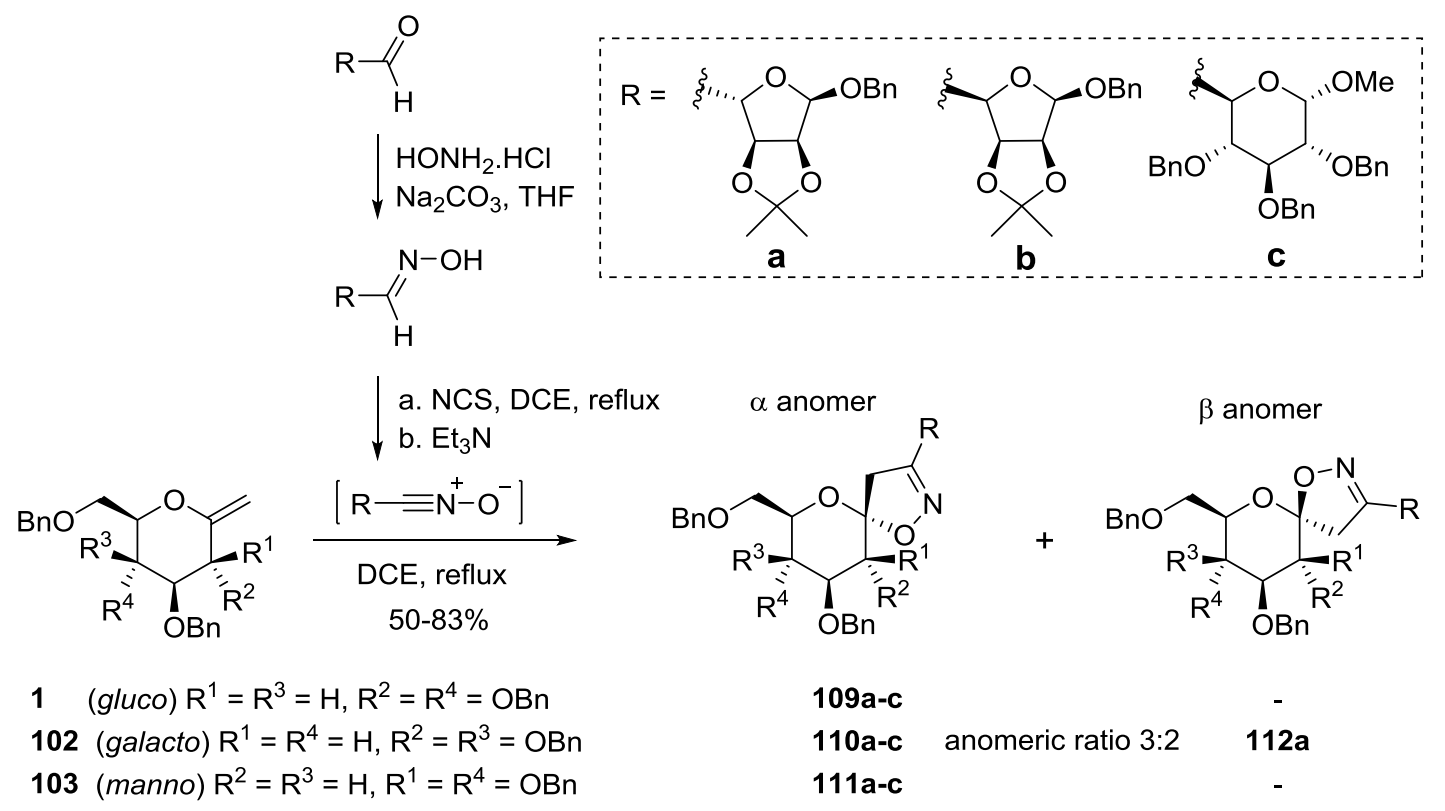

Scheme 25. Reaction between exo-glycals and sugar nitrile oxides 


\subsection{Intramolecular cycloadditions}

Recently, Das et al. published some examples of intramolecular cycloadditions on unsaturated sugar nitrones (Scheme 26) [13]. Starting from sugar olefins 113-116, the alcohol function was oxidized by Dess-Martin Periodinane (DMP) or oxalyle chloride and dimethylsulfoxide, followed by condensation of $N$-benzyl hydroxylamine on the aldehyde. The unstable nitro compounds underwent intramolecular cyclization to furnish exclusively seven-membered rings spiro-isoxazolidines 117-120. Stereochemistry of the cycloadducts was assigned with NMR analysis and X-Ray crystallography. This method thus enables the formation of furanose-fused oxepane (117), thiepane (118), azepane (119) and cycloheptane (120). In the case of olefin 121, attack of the oxanion occurred on the unsubstituted carbon of the double bond, leading to five-membered carbocycle 122 in good yield.

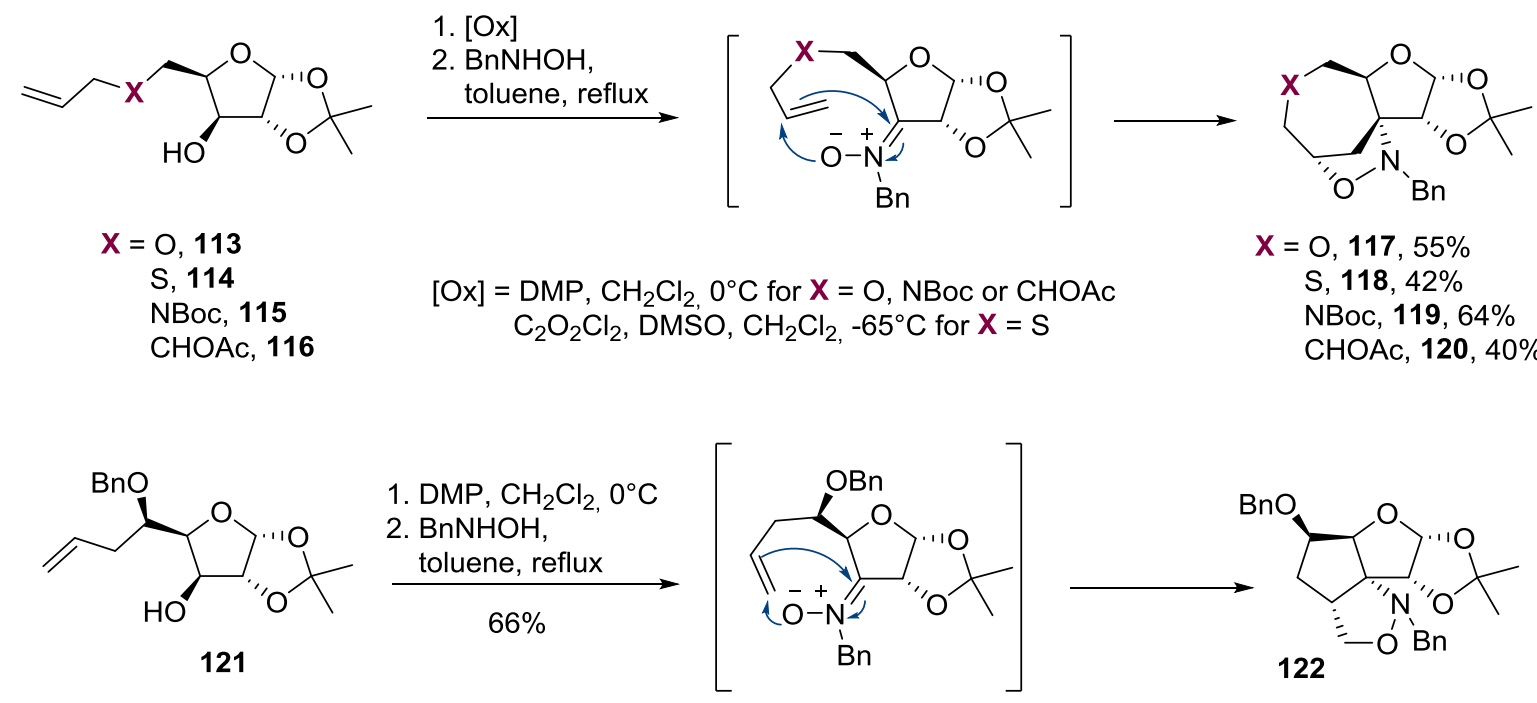

Scheme 26. Intramolecular nitro-olefin cycloaddition

Furthermore, they took advantage of the labile nature of the $\mathrm{N}-\mathrm{O}$ bond to prepare original bicyclic nucleosides derivatives (Scheme 27). Cleavage of the isoxazolidine ring of 117 and 122 was carried out with molybdenum hexacarbonyl in refluxing aqueous acetonitrile, leading to $\mathbf{1 2 3}$ and 124 in 77 and $71 \%$ yields respectively. After deprotection of the sugar 1,2 diol of compounds 123 and 124 and subsequent acetylation of the free amino and hydroxyl groups, the fully protected compounds underwent glycosylation in Vorbrüggen conditions to give nucleosides 125 and 126 in 45 and $41 \%$ yields. 


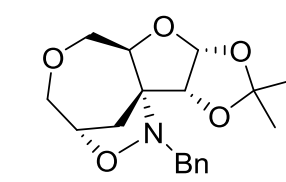

117

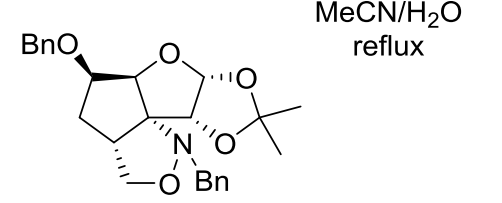

122

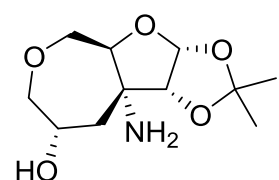

$123,77 \%$

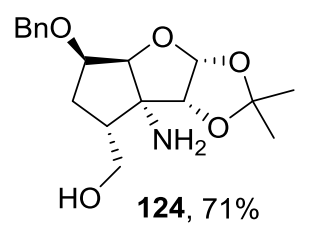

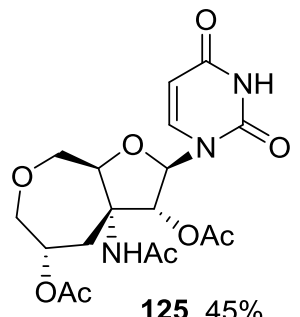

1. $\mathrm{Ac}_{2} \mathrm{O}, \mathrm{TfOH}$,

$\mathrm{AcOH}, 0^{\circ} \mathrm{C}$

2. Uracil, BSA, TMSOTf $\mathrm{MeCN}, 50^{\circ} \mathrm{C}$

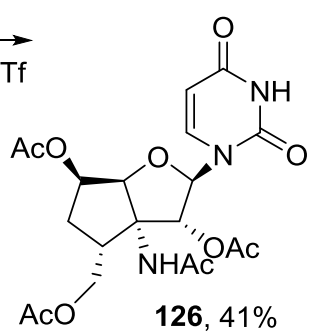

Scheme 27. Preparation of bicyclic nucleosides

\section{Conclusion}

The 1,3-dipolar cycloaddition reaction between an olefin and a nitrile oxide or a nitrone is an efficient way to prepare isoxazolines and isoxazolidines, respectively. The adaptation of this reaction on saccharidic systems has been studied in the literature for several decades. In this chapter, we put the emphasis on the preparation of saccharidic spiro derivatives containing these heterocycles, an unexplored subject until the preliminary results of Rajanbabu et al. in 1986. Since then, the syntheses of saccharidic spiro-isoxazoli(di)nes have been expanded on various types of olefins, notably exo-methylene sugars or activated exo-glycals. The cycloaddition proceeds in many cases with high regio- and stereocontrol and the stereochemistry of adducts can be established by NMR experiments and/or X-ray analyses. Elegant examples involving sugar-based nitrile oxides and nitrones and also intramolecular cycloadditions were reported and paved the way to the preparation of original bicyclic systems and various carbocycles. In several examples, the properties of the obtained saccharidic cycloadducts were investigated for various biological applications such as spironucleoside analogues, antibacterial agents or enzyme inhibitors. In addition to their biological properties and taking into account the originality of their structures, these systems were utilized as sugar scaffolds and proved suitable for selective derivatization.

\section{References}

1. Berthet M, Cheviet T, Dujardin G, Parrot I, Martinez J (2016) Isoxazolidine: A Privileged Scaffold for Organic and Medicinal Chemistry. Chem Rev 116:15235-15283

2. Tufariello JJ (1984) Nitrones. In: 13-Dipolar Cycloaddit. Chem. Wiley, pp 83-168

3. Confalone PN, Huie EM (2004) The [3 + 2] Nitrone-Olefin Cycloaddition Reaction. In: Org. React. American Cancer Society, pp 1-173

4. Padwa A, Pearson WH (eds) (2002) Synthetic Applications of 1,3-Dipolar Cycloaddition Chemistry Toward Heterocycles and Natural Products 
5. Gothelf KV (2001) Asymmetric Metal-Catalyzed 1,3-Dipolar Cycloaddition Reactions. In: Cycloaddit. React. Org. Synth. Wiley-Blackwell, pp 211-247

6. Padwa A (1984) 1,3-dipolar cycloaddition chemistry. New York: Wiley

7. Kaur K, Kumar V, Sharma AK, Gupta GK (2014) Isoxazoline containing natural products as anticancer agents: A review. Eur J Med Chem 77:121-133

8. Frederickson M (1997) Optically active isoxazolidines via asymmetric cycloaddition reactions of nitrones with alkenes: applications in organic synthesis. Tetrahedron 53:403-425

9. Gothelf KV, Jørgensen KA (1998) Asymmetric 1,3-Dipolar Cycloaddition Reactions. Chem Rev 98:863-910

10. Giuliano RM (1992) Cycloaddition Reactions in Carbohydrate Chemistry. In: Cycloaddit. React. Carbohydr. Chem. American Chemical Society, pp 1-23

11. Paton RM (1998) The Nitrile Oxide/Isoxazoline Route to C-Disaccharides. In: Carbohydr. Mimics. Wiley-Blackwell, pp 49-66

12. Osborn HMI, Gemmell N, Harwood LM (2002) 1,3-Dipolar cycloaddition reactions of carbohydrate derived nitrones and oximes. J Chem Soc Perkin $12419-2438$

13. Das SN, Chowdhury A, Tripathi N, Jana PK, Mandal SB (2015) Exploitation of in Situ Generated Sugar-Based Olefin Keto-Nitrones: Synthesis of Carbocycles, Heterocycles, and Nucleoside Derivatives. J Org Chem 80:1136-1148

14. Taillefumier C, Chapleur Y (2004) Synthesis and Uses of exo-Glycals. Chem Rev 104:263292

15. Pellegrini-Moïse N, Richard M, Chapleur Y (2014) Chapter 6. Exo -glycals as useful tools for anomeric functionalization of sugars. In: Pilar Rauter A, Lindhorst T, Queneau Y (eds) Carbohydr. Chem. Royal Society of Chemistry, Cambridge, pp 99-117

16. RajanBabu TV, Reddy GS (1986) 1-Methylene sugars as C-glycoside precursors. J Org Chem 51:5458-5461

17. Colinas PA, Jager V, Lieberknecht A, Bravo RD (2003) Nitrile oxide cycloadditions to olefinated sugars. Tetrahedron Lett 44:1071-1074

18. Benltifa M, Vidal S, Gueyrard D, Goekjian PG, Msaddek M, Praly J-P (2006) 1,3-Dipolar cycloaddition reactions on carbohydrate-based templates: synthesis of spiro-isoxazolines and 1,2,4oxadiazoles as glycogen phosphorylase inhibitors. Tetrahedron Lett 47:6143-6147

19. Benltifa M, Hayes JM, Vidal S, David Gueyrard, Goekjian PG, Praly JP, Kizilis G, Tiraidis C, Alexacou KM, Chrysina ED, Zographos SE, Leonidas DD, Archontis G, Oikonomakos NG (2009) Glucose-based spiro-isoxazolines: A new family of potent glycogen phosphorylase inhibitors. Bioorg Med Chem 17:7368-7380

20. Krimm I, Lancelin J-M, Praly J-P (2012) Binding Evaluation of Fragment-Based Scaffolds for Probing Allosteric Enzymes. J Med Chem 55:1287-1295

21. Goyard D, Kónya B, Chajistamatiou AS, Chrysina ED, Leroy J, Balzarin S, Tournier M, Tousch D, Petit P, Duret C, Maurel P, Somsak L, Docsa T, Gergely P, Praly JP, Azay-Milhau J, Vidal S, (2016) Glucose-derived spiro-isoxazolines are anti-hyperglycemic agents against type 2 diabetes through glycogen phosphorylase inhibition. Eur J Med Chem 108:444-454 
22. Somsák L, Bokor É, Czibere B, Czifrak K, Koppany C, Kulcsar L, Kun S, Szilagyi E, Toth M, Docsa T, Gergely P (2014) Synthesis of C-xylopyranosyl- and xylopyranosylidene-spiro-heterocycles as potential inhibitors of glycogen phosphorylase. Carbohydr Res 399:38-48

23. Goyard D, Telligmann SM, Goux-Henry C, Boysen MMK, Framery E, Gueyrard D, Vidal S (2010) Carbohydrate-based spiro bis(isoxazolines): synthesis and evaluation in asymmetric catalysis. Tetrahedron Lett 51:374-377

24. Li X, Takahashi H, Ohtake H, Ikegami S (2003) Synthesis of Ketosyl spiro-Isoxazolidine by 1,3-Dipolar Cycloaddition of 1-Methylenesugars with Nitrones - A New Access to C-Glycosyl Amino Acids. ChemInform. doi: 10.1002/chin.200331221

25. Ikegami S, Namme R (2009) Chemistry of 1-Methylenesugars: Synthetic Utilizations to 1'-CMethyl-saccharides and Related Carbohydrates. Heterocycles 78:19-44

26. Li X, Wang R, Wang Y, Chen H, Li Z, Ba C, Zhang J (2008) Stereoselective synthesis and biological activity of novel spiro-oxazinanone-C-glycosides. Tetrahedron 64:9911-9920

27. Gallos JK, Koftis TV, Koumbis AE, Moutsos VI (1999) A novel Carbocyclic Ring Closure of Hex-5-enopyranosides and Pent-4-enofuranosides. Synlett 1999:1289-1291

28. Gallos JK, Demeroudi SC, Stathopoulou CC, Dellios CC (2001) Expeditious synthesis of seven-membered iminocyclitols. Tetrahedron Lett 42:7497-7499

29. Gallos JK, Koftis TV (2001) Carbocyclic ring closure of hex-5-enopyranosides and pent-4enofuranosides: a nitrile oxide approach. J Chem Soc Perkin 1 415-423

30. Lakhrissi M, Chapleur Y (1996) Wittig Olefination of Lactones. Angew Chem Int Ed Engl $35: 750-752$

31. Enderlin G, Taillefumier C, Didierjean C, Chapleur Y (2005) Cycloaddition reactions on activated exo-glycals. Tetrahedron Asymmetry 16:2459-2474

32. C. Taillefumier, G. Enderlin , Y. Chapleur (2005) Cycloaddition of Nitrones and Nitrile Oxides to Activated Exo-glycals. Lett Org Chem 2:226-230

33. Salgado H, Jiménez R, Pérez L, Tamariz J, Salgado H (1993) 1,3-Dipolar Cycloaddition Reactions Involving Captodative Olefins. Heterocycles 35:591-598

34. Nakajima M, Itoi K, Takamatsu Y, Kinoshita T, Okazaki T, Kawakubo K, Shindo M, Honma T, Tohjigamori M, Haneishi T (1991) Hydantocidin: A new compound with herbicidal activity from Streptomyces hygroscopicus. J Antibiot (Tokyo) 44:293-300

35. Richard M, Chapleur Y, Pellegrini-Moïse N (2016) Spiro sugar-isoxazolidine scaffold as useful polyfunctional building block for peptidomimetics design. Carbohydr Res 422:24-33

36. Novoa A, Pellegrini-Moïse N, Bechet D, Barberi-Heyob M, Chapleur Y (2010) Sugar-based peptidomimetics as potential inhibitors of the vascular endothelium growth factor binding to neuropilin-1. Bioorg Med Chem 18:3285-3298

37. Richard M, Chateau A, Jelsch C, Didierjean C, Manival X, Charron C, Maigret B, BarberiHeyob M, Chapleur Y, Boura C, Pellegrini-Moïse N (2016) Carbohydrate-based peptidomimetics targeting neuropilin-1: Synthesis, molecular docking study and in vitro biological activities. Bioorg Med Chem 24:5315-5325 
38. Gong C, Valduga J, Chateau A, Richard M, Pellgrini-Moïse N, Barberi-Heyob M, Chastagner P, Boura C (2018) Stimulation of medulloblastoma stem cells differentiation by a peptidomimetic targeting neuropilin-1. Oncotarget. 9:15312-15325.

39. Li X, Takahashi H, Ohtake H, Ikegami S (2004) 1,3-Dipolar cycloaddition of exo methylenesugars with nitrone: approach to new amino- C -ketosyl disaccharides. Tetrahedron Lett 45:4123-4126

40. Oukani H, Pellegrini-Moïse N, Jackowski O, Chrétien F, Chapleur Y (2013) The 1,3-dipolar cycloaddition reaction of chiral carbohydrate-derived nitrone and olefin: towards long-chain sugars. Carbohydr Res 381:205-214

41. Vasella A, Voeffray R (1982) Total synthese von Nojirimycin. Helv Chim Acta 65:1134-1144

42. Vasella A, Voeffray R, Pless J, Huguenin R (1983) Synthesis of D- and L-5-Oxaproline and of a New Captopril Analogue. Helv Chim Acta 66:1241-1252

43. Tronchet JMJ, Mihaly E (1972) C-glycosylic derivatives. VII. Synthesis and reactions of sugar nitrones. Helv Chim Acta 55:1813-1815

44. Torrente S, Noya B, Paredes MD, Alonso R (1997) Intramolecular 1,3-Dipolar Cycloadditions of Sugar Ketonitrones: A Convenient Method for Stereoselective Formation of Nitrogenated Quaternary Centers. J Org Chem 62:6710-6711

45. Hossain N, Papchikhin A, Plavec J, Chattopadhyaya J (1993) Synthesis of 2'- and 3'-Spiroisoxazolidine Derivatives of Thymidine \& Their Conversions to 2',3'-dideoxy-2',3'-didehydro3'Qsubstituted nucleosides by Radical Promoted Fragmentation. Tetrahedron 49:10133-10156

46. Rong J, Roselt P, Plavec J, Chattopadhyaya J (1994) The synthesis and conformation of 2'and 3'-hypermodified tricyclic nucleosides and their use in the synthesis of novel 2'- or 3'-isomeric 4(7)-substituted isoxazolidine-nucleosides. Tetrahedron 50:4921-4936

47. Torrente S, Noya B, Branchadell V, Alonso R (2003) Intra- and Intermolecular 1,3-Dipolar Cycloaddition of Sugar Ketonitrones with Mono-, Di-, and Trisubstituted Dipolarophiles. J Org Chem 68:4772-4783

48. Yokoyama M, Yamada N, Togo H (1990) Synthesis of Spiro Sugar Isoxazolidines via Tandem Michael Addition-1,3-dipolar Cycloaddition. Chem Lett 19:753-756

49. Yokoyama M, Sujino K, Irie M, Yamazaki N, Hiyama T, Yamada N, Togo H (1991) Additional reactions of sugar oximes, nitrite oxides and hydroximolactones. J Chem Soc Perkin 1 0:2801-2809

50. Grigg R, Markandu J, Perrior T, Surendrakumar S, Warnock WJ (1992) X = Y - ZH systems as potential 1,3-dipoles part 35. Generation of nitrones from oximes. Class 3 processes. Tandem intramolecular michael addition (1,3-azaprotio cyclotransfer) - intermolecular 1,3-dipolar cycloaddition reactions. Tetrahedron 48:6929-6952

51. Yokoyama M, Yamada N (1989) Synthesis of spiro and bicyclic nucleosides from ribose nitrile oxide with dimethyl acetylenedicarboxylate. Tetrahedron Lett 30:3675-3676

52. Zhang PZ, Li XL, Chen H, Li YN, Wang R (2007) The synthesis and biological activity of novel spiro-isoxazoline $\mathrm{C}$-disaccharides based on 1,3-dipolar cycloaddition of exo-glycals and sugar nitrile oxides. Tetrahedron Lett 48:7813-7816 